September 2004 • NREL/SR-510-36391

\title{
Kinetic and Modeling Investigation on Dilute Sulfuric Acid and Hot Water Fractionation of Selected Biomass Plan
}

\section{May 1997}

Y.Y. Lee, R.B. Chen, Z. Wu, and J. Hayes Auburn University Auburn, Alabama
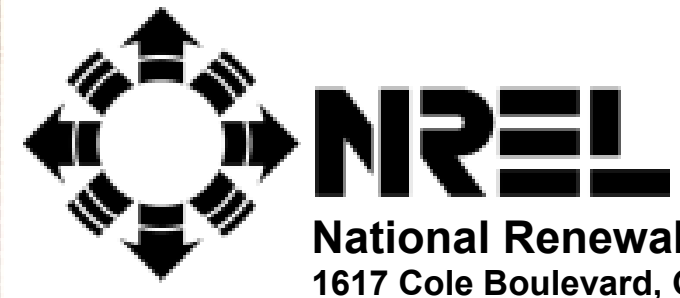

National Renewable Energy Laboratory 1617 Cole Boulevard, Golden, Colorado 80401-3393 303-275-3000 • www.nrel.gov

Operated for the U.S. Department of Energy Office of Energy Efficiency and Renewable Energy by Midwest Research Institute • Battelle 


\section{Kinetic and Modeling Investigation on Dilute Sulfuric Acid and Hot Water Fractionation of Selected Biomass Plan}

\section{May 1997}

Y.Y. Lee, R.B. Chen, Z. Wu, and J. Hayes Auburn University Auburn, Alabama

NREL Technical Monitor: R. Torget

Prepared under Subcontract No. XAW-3-13441-01

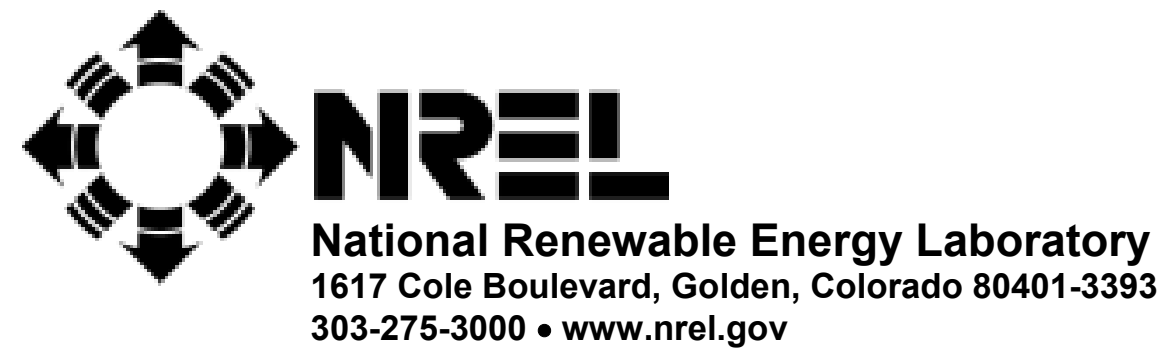

Operated for the U.S. Department of Energy Office of Energy Efficiency and Renewable Energy by Midwest Research Institute $\bullet$ Battelle Contract No. DE-AC36-99-G010337 
This publication was reproduced from the best available copy Submitted by the subcontractor and received no editorial review at NREL

\section{NOTICE}

This report was prepared as an account of work sponsored by an agency of the United States government. Neither the United States government nor any agency thereof, nor any of their employees, makes any warranty, express or implied, or assumes any legal liability or responsibility for the accuracy, completeness, or usefulness of any information, apparatus, product, or process disclosed, or represents that its use would not infringe privately owned rights. Reference herein to any specific commercial product, process, or service by trade name, trademark, manufacturer, or otherwise does not necessarily constitute or imply its endorsement, recommendation, or favoring by the United States government or any agency thereof. The views and opinions of authors expressed herein do not necessarily state or reflect those of the United States government or any agency thereof.

Available electronically at http://www.osti.gov/bridge

Available for a processing fee to U.S. Department of Energy and its contractors, in paper, from:

U.S. Department of Energy

Office of Scientific and Technical Information

P.O. Box 62

Oak Ridge, TN 37831-0062

phone: 865.576.8401

fax: 865.576 .5728

email: mailto:reports@adonis.osti.gov

Available for sale to the public, in paper, from:

U.S. Department of Commerce

National Technical Information Service

5285 Port Royal Road

Springfield, VA 22161

phone: 800.553 .6847

fax: 703.605.6900

email: orders@ntis.fedworld.gov

online ordering: http://www.ntis.gov/ordering.htm 


\section{TABLE OF CONTENTS}

Task 1. Modeling and Simulation of a Shrinking bed Reactor Operation of Pretreatment.

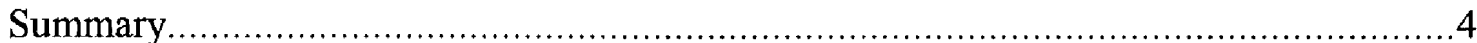

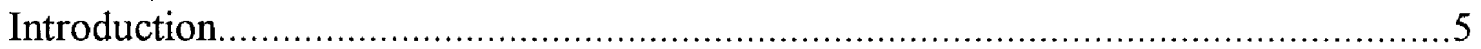

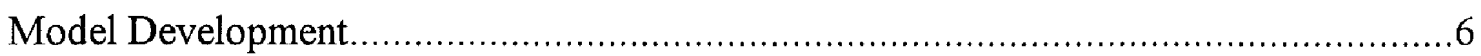

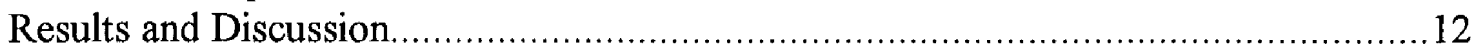

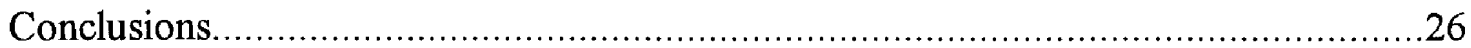

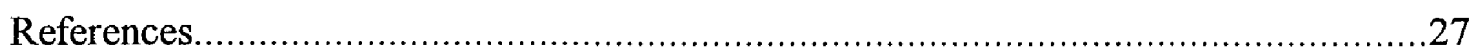

Task2. Biomass Pretreatment with Carbonic Acid...........................................................28

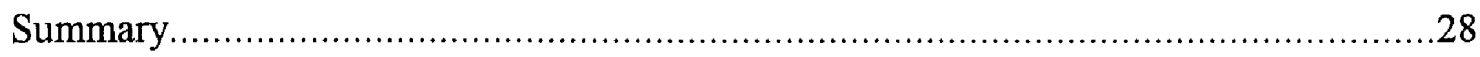

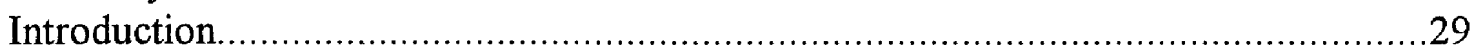

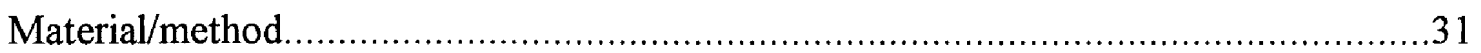

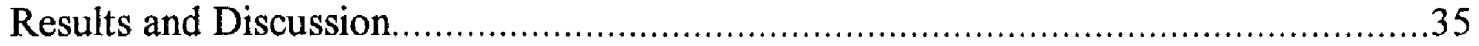

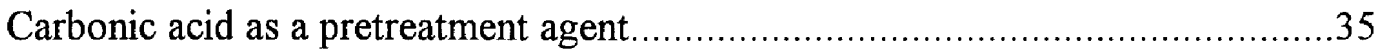

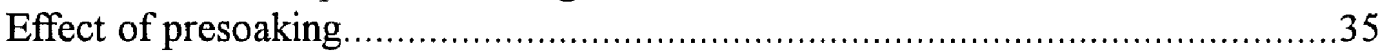

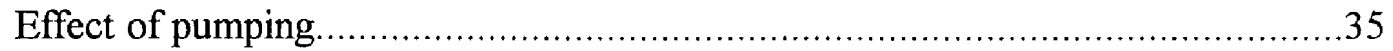

Carbonic acid pretreatment with ambient front pressure...................................38

Carbonic acid pretreatment with front and back pressure...................................41

Optimization of pressurized carbonic acid pretreatment .....................................43

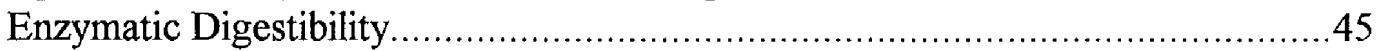

Hemicellulose removal and parameters optimization.......................................45

Variation of second stage reaction temperature..............................................48

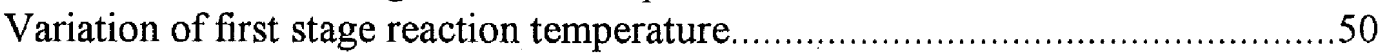

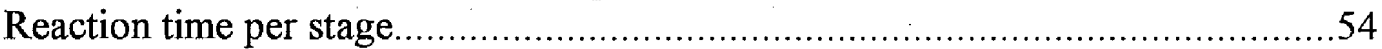

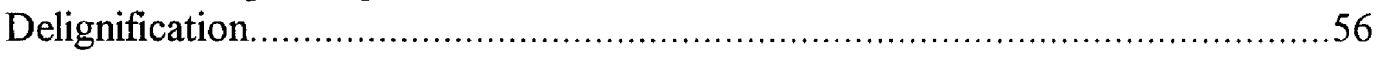

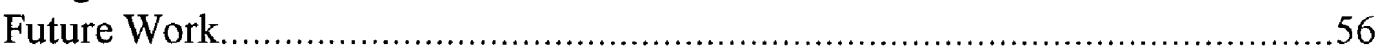

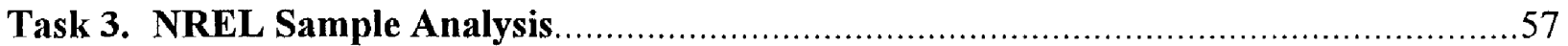

Appendix 1. Fortran Source Codes for Modeling and Simulation of a Shrinking bed Reactor Operation of Pretreatment. 


\section{ABBREVIATIONS}

$\mathrm{C}_{0} \quad$ initial xylan concentration in percolation, $\%$

$\mathrm{H}$ concentration of hemicellulose as xylose in the reactor

$\mathrm{k}_{0 \mathrm{i}} \quad$ frequency factor for $\mathrm{k}_{\mathrm{i}}$

$\mathrm{k}_{\mathrm{i}} \quad$ rate constant $=\mathrm{A}^{\mathrm{ni}} \mathrm{k}_{\mathrm{oi}} \mathrm{exp}\left(\mathrm{E}_{\mathrm{i}} / \mathrm{RT}\right), \min ^{-1}$

$\mathrm{L} \quad$ reactor length, $\mathrm{cm}$

u

V

Y

velocity inside percolation reactor, $\mathrm{cm} / \mathrm{min}$

reactor volume

yield

\section{Greek}

$\beta_{\mathrm{i}}$

$\gamma$

$\eta$

$\theta$

$\xi$

$\tau$

$\mathrm{k}_{\mathrm{i}} \mathrm{L} / \mathrm{u}$

ratio of solubilized lignin to solubilized hemicellulose

composition of hemicellulose in solid biomass

conversion of hemicellulose during hydrolysis

shrinking factor, the ratio of the reactor volume after a compression operation to that of before the compression operation

tu/L

\section{Subscript}

0

value at $\mathrm{t}=0$

ns

non-shrinking bed operation

overall

overall value based on initial condition

S

shrinking bed operation

\section{Superscript}

i

$i$ th operation

$j$ th operation 


\title{
Task 1. Modeling and Simulation of a Shrinking Bed Reactor Operation of Pretreatment.
}

\begin{abstract}
For many lignocellulosic substrates, hemicellulose is known to be biphasic upon dilute acid treatment. The biphasic nature of the substrate led to a modified percolation process employing simulated two-stage reverse-flow. This process has been proven, both theoretically and experimentally, to improve the process attaining substantially higher sugar yield and concentration over the conventional percolation process. The dilute-acid pretreatment of biomass is basically a solubilization of the hemicellulose fraction in the solid biomass. As the reaction proceeds the hemicellulose is removed leaving less amount of solid biomass in the reactor. This creates a situation whereby the depth of the bed is continually reduces. A bed-shrinking model was therefore developed to describe the two-stage reverse flow reactor operated for hydrolysis of a biphasic substrates including hemicellulose in corn cob/stover mixture (CCSM). The simulation results indicate that the shrinking bed operation increases the sugar yield by about $5 \%$ in comparison to the non-shrinking bed operation at a representative $\tau$ value of 1.0 . A simulated optimal run further reveals that fast portion of hemicellulose is almost completed hydrolyzed in the first stage, the slow portion of hemicellulose being hydrolyzed in the second stage. Under optimum condition, the bed shrinkage reached $27 \%$ (a near maximum value) and the sugar yield upward of $95 \%$ was attainable.
\end{abstract}




\section{INTRODUCTION}

Pretreatment is a necessary a necessary element in the bioconversion of lignocellulosic biomass into fuels and chemicals. Treatment with dilute sulfuric acid is one of viable process options in the biomass pretreatment. A concern, however, arises in this approach that the sugars are decomposed under high temperature and low $\mathrm{pH}$ to form undesirable components that are toxic to the subsequent fermentation microorganism. It is an important issue to select proper reaction conditions, reactor configurations, and operation conditions. Previous studies along these lines(1-4) have established that a percolation reactor (packed-bed flow through type) is one of the reactor types most suitable for biomass pretreatment. In operation of this reactor, the sugar products are discharged from the reactor as they are formed thus reducing sugar decomposition. High sugar concentration can also be attained due to high solid to liquid ratio that exists in a packed-bed reactor. In the ensuing modeling and experimental work $(5,6)$ it was demonstrated that a two-stage, two-temperature, reverse-flow scheme significantly enhances the overall performance of the percolation reactor. This particular design was introduced to simulate counter-current flow of the biomass solid and hydrolysis liquor and to exploit from the fact that hemicellulose exhibits a biphasic behavior upon dilute acid hydrolysis. In the temperature policy, a low temperature is applied in the first stage to hydrolyze the easily hydrolyzable xylan, then a high temperatures applied in the second stage to hydrolyze the resilient fraction of the xylan.

The acid based pretreatment of biomass is basically a solubilization of hemicellulose in biomass. In our previous modeling work (5), an assumption was made that the bulk packing volume of the solid biomass in the reactor remains constant during the hydrolysis. It was done so to retain the linearity of the governing equations. However, in actual operation, the bulk packing 
density of the solid biomass in the reactor is indeed changing due to solubilization of the hemicellulose. As the reaction proceeds the hemicellulose is removed leaving less solid biomass in the reactor. To further optimize the pretreatment process, a shrinking bed reactor was proposed by NREL (7). It was designed to keep the bulk packing density of the solid biomass in the reactor at a constant level such that a high solid:liquid ratio, consequently a high product concentration can be obtained. Figure 1 shows a simplified diagram of a shrinking bed, percolation reactor. The reactor has a fixed and a movable end. The movable end is supported by a compressed spring. The gradual depletion of the packed solid biomass as the reaction progresses in the bed causes the particle structure to be less dense. The spring-attached movable end then moves forward to press the loose biomass particles closer. By this mechanism, the bulk packing density of the lignocellulosic biomass can be maintained at a constant level. In this work, a process modeling and simulation was carried out for this shrinking bed reactor as it is applied to the acid hydrolysis of lignocellulosic.

The investigation was undertaken to establish a process model for the shrinking bed reactor operating prehydrolysis reaction on the hemicellulose of corn cobs/stover mixture (CCSM). The modeling work was directed toward optimal operation of the shrinking-bed reactor and analysis on the bed-shrinking phenomena. The issues addressed in the modeling and simulation were the extent and the effect of bed-shrinking, substrate variation in the reactor, product yield and concentration.

\section{MODEL DEVELOPMENT}

The shrinking bed reactor is still a percolation reactor with solid bed gradually shrinking 
during the hydrolysis. The shrinkage occurs because of solubilization of hemicellulose in solid biomass (Figure 1). The effective volume of the reactor (or length of solid bed of biomass in the percolation reactor) is related to hemicellulose conversion. For a differential value of $\tau^{\mathrm{i}}$, or a differential amount of acid fluid, the percolation process can be assumed to be a non-shrinking bed reactor since a differential amount of hemicellulose is removed during that time span. The non-shrinking process is then followed by a compression stage in which only compression of the biomass occurs to regain its original packing density. It is assumed that no reaction occurs in this stage. The model development for the shrinking bed reactor operation can be decoupled, as shown in Figure 2, to repeated operation of non-shrinking bed reaction with a differential amount of liquid $\tau^{\mathrm{i}}$ followed by a compression process. Adoption of this method allows the governing partial differential equations to be in linear form. Therefore the analytical solution previously obtained for non-shrinking bed operation (5) becomes directly applicable to the present case..

A shrinking factor $\xi \mathrm{i}$ is defined as the ratio of the reactor volume after the $i$ th compression operation to that before the $i$ th compression operation.

$$
\xi^{i}=\frac{V^{i}}{V^{i-1}}
$$

For the cylinder reactor, Equation (1) can also be expressed as, in terms of reactor length,

$$
\xi^{i}=\frac{L^{i}}{L^{i-1}}
$$

$\xi^{\mathrm{i}}(\leq 1)$ is the function of hemicellulose conversion only. 


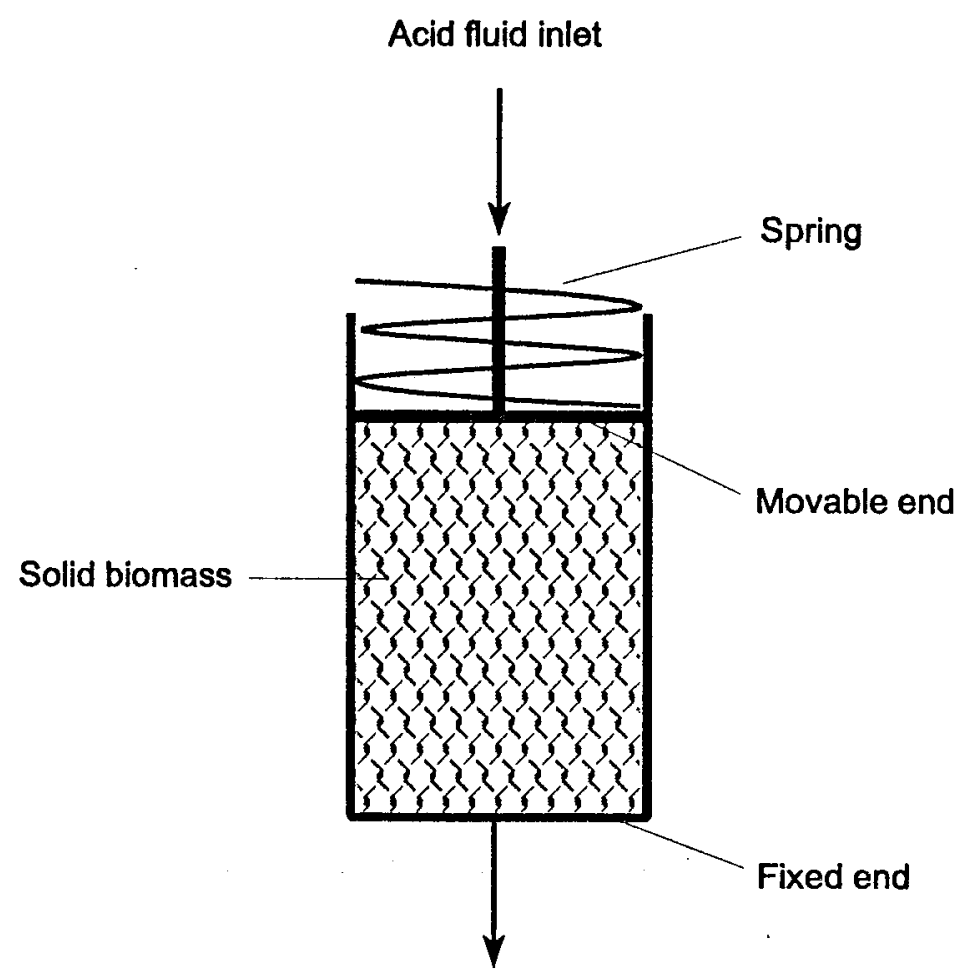

Acid fluid outlet

Figure 1. A simplified diagram of a shrinking bed reactor applied in pretreatment 


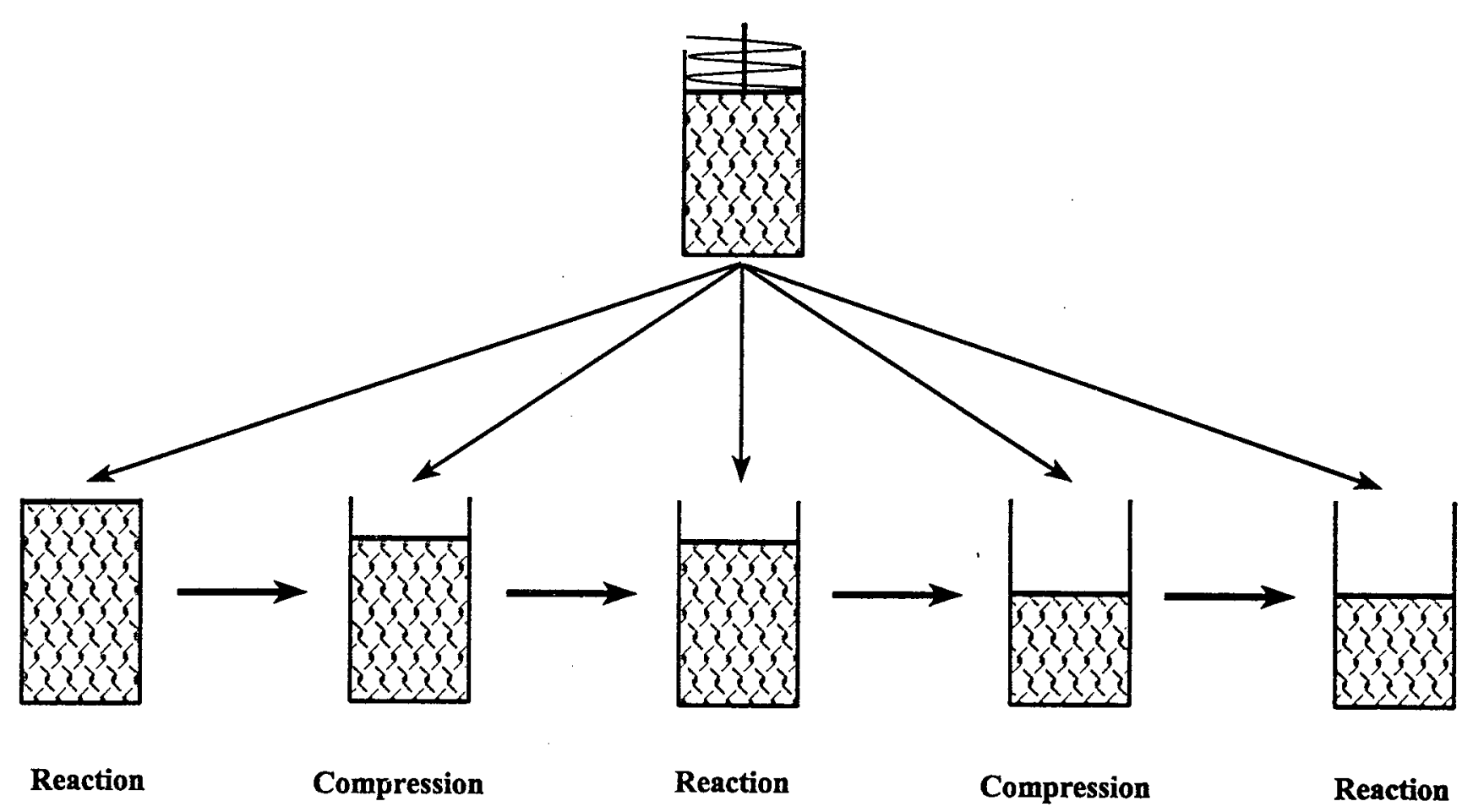

Figure 2. Decomposition of a shrinking bed reactor 
The conversion of hemicellulose during one differential value of $\tau^{\mathrm{i}}$ in non-shrinking operation is

$$
\theta^{\mathrm{i}}=\frac{\mathrm{H}^{\mathrm{i}-1}-\mathrm{H}^{\mathrm{i}}}{\mathrm{H}^{\mathrm{i}-1}}
$$

This equation is valid only for the non-shrinking bed operation. The hemicellulose concentration in the reactor $\mathrm{H}^{\mathrm{i}-1}$ and $\mathrm{H}^{\mathrm{i}}$ are determined by Equation (8) in reference (5).

The composition $\left(\eta^{\mathrm{i}}\right)$ of hemicellulose in the solid biomass is subject to change during the hydrolysis as hemicellulose and partial lignin are solubilized into the hydrolyzate. It can, based on material balance, be expressed as

$$
\eta^{i}=\frac{\eta^{i-1}\left(1-\theta^{i}\right)}{1-\eta^{i-1} \theta^{i}(1+\gamma)}
$$

where $\gamma$ is the ratio of solubilized lignin to solubilized hemicellulose during the pretreatment. It is assumed to be constant throughout the reaction. For the sample substrate of CCSM with $20.0 \%$ xylan, $39.2 \%$ glucan, and $23.3 \%$ lignin (8), it was assumed that $80 \%$ of total lignin was dissolved with the solubilization of hemicellulose and cellulose. Therefore the $\gamma$ value is calculated to be 0.315 from the composition data of the feedstock.

The change of reactor volume resulting from the solubilization of hemicellulose and partial lignin is expressed as

$$
\mathrm{V}^{\mathrm{i}}=\mathrm{V}^{\mathrm{i}-1}\left[1-\eta^{\mathrm{i}-1} \theta^{\mathrm{i}-1}(1+\gamma)\right]
$$


Therefore, the shrinking factor is determined by

$$
\xi^{\mathrm{i}}=1-\eta^{\mathrm{i}-1} \theta^{\mathrm{i}}(1+\gamma)
$$

for one stage of compression operation.

The overall reaction conversion $\left(\theta_{\text {overall }}\right)$ after the $n$th non-shrinking and compression operations, based on the initial reaction conditions, is expressed as:

$$
\theta_{\text {overall }}=1-\frac{\mathrm{H}_{\mathrm{n}}}{\mathrm{H}_{\mathrm{o}}} \prod_{\mathrm{i}=1}^{\mathrm{n}} \xi^{\mathrm{i}}
$$

Similarly, the overall length of the shrinking bed reactor during the reaction is:

$$
\mathrm{L}=\mathrm{L}_{\mathrm{o}} \prod_{\mathrm{i}=1}^{\mathrm{n}} \xi^{\mathrm{i}}
$$

The yield obtained from the non-shrinking model should be converted to that from shrinking model. The overall yield is determined by the sum of yield from non-shrinking bed operation model with consideration of the compression operation. It is then expressed as:

$$
\mathrm{Y}_{\mathrm{s}}=\frac{1}{\mathrm{H}_{\mathrm{o}}} \sum_{\mathrm{j}=1}^{\mathrm{n}}\left(\mathrm{Y}_{\mathrm{ns}}^{\mathrm{j}} \mathrm{H}^{\mathrm{j}} \prod_{\mathrm{i}=1}^{\mathrm{j}} \xi^{\mathrm{j}}\right)
$$

where $\mathrm{Y}_{\mathrm{s}}=$ sugar yield from shrinking bed operation,

$\mathrm{Y}_{\mathrm{ns}}=$ sugar yield from non-shrinking bed operation (5),

$\mathrm{H}_{\mathrm{o}}=$ initial concentration of hemicellulose as xylose in the reactor, $\mathrm{j}=1,2, \ldots . \mathrm{n}, \quad \mathrm{I}=1,2, \ldots \mathrm{j}$. 


\section{RESULTS AND DISCUSSION}

The shrinking bed operation is quite similar to the non-shrinking bed operation except that there is a compression stage between each non-shrink reaction process which undergoes a differential reaction period of $\tau^{\mathrm{i}}$ in the shrinking bed operation. The compression process increases the solid packing density to its previous level. This compression process will not change the biomass composition but only the initial solid concentration. Therefore, the optimum temperature step-change applied to the non-shrinking operation is also applied to the shrinking bed operation, and they were used in the shrinking process. The bed depth in the shrinking bed operation is changing during the reaction. The optimum flow rate therefore needs to be adjusted in response to the reduced liquid residence time. The actual computation of the modeling work was done for CCSM. A two-stage reverse flow operation (Figure 3A), is identical in theory to the process shown in Figure 3B(5). The shrinking bed process was modeled and simulated on the basis of the scheme of Figure 3B.

\section{Effect of acid flow rate and $\tau$}

In the previous non-shrinking bed model, the optimum flow rate (from $\beta_{\mathrm{i}}=\mathrm{k}_{\mathrm{i}} \mathrm{L} / \mathrm{u}$ ) is obtained for a given reactor length at certain temperature (5). The term $\beta_{\mathrm{i}}$ is an optimized operational parameter. If the length of the reactor is reduced, the flow rate of the liquid $u$ should also be reduced to maintain the parameter at its optimum. However, this operation is not convenient in the practical application. We have studied the effect of flow rate of acid fluid on sugar yield by applying a constant flow rate operation. Figure 4 shows the effect of flow rate on sugar yield at optimum temperature step change $\left(140-170^{\circ} \mathrm{C}\right)$. For a given $\tau$, there is an 


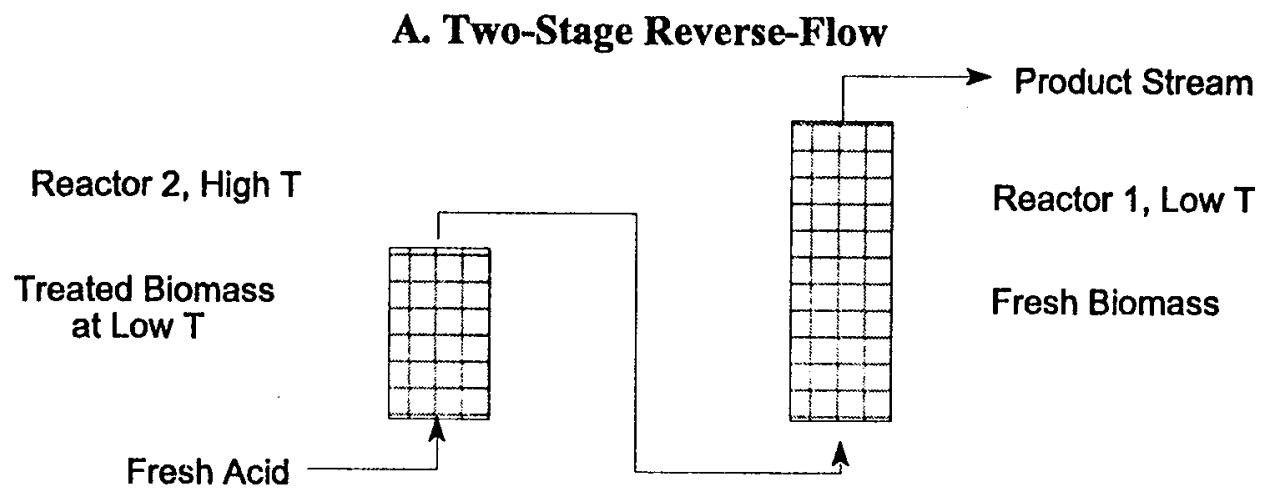

B. Two-Stage Reverse-Flow (Artificial)

Reactor $1=$ Reactor $1 \mathrm{a}+$ Reactor $1 \mathrm{~b}$

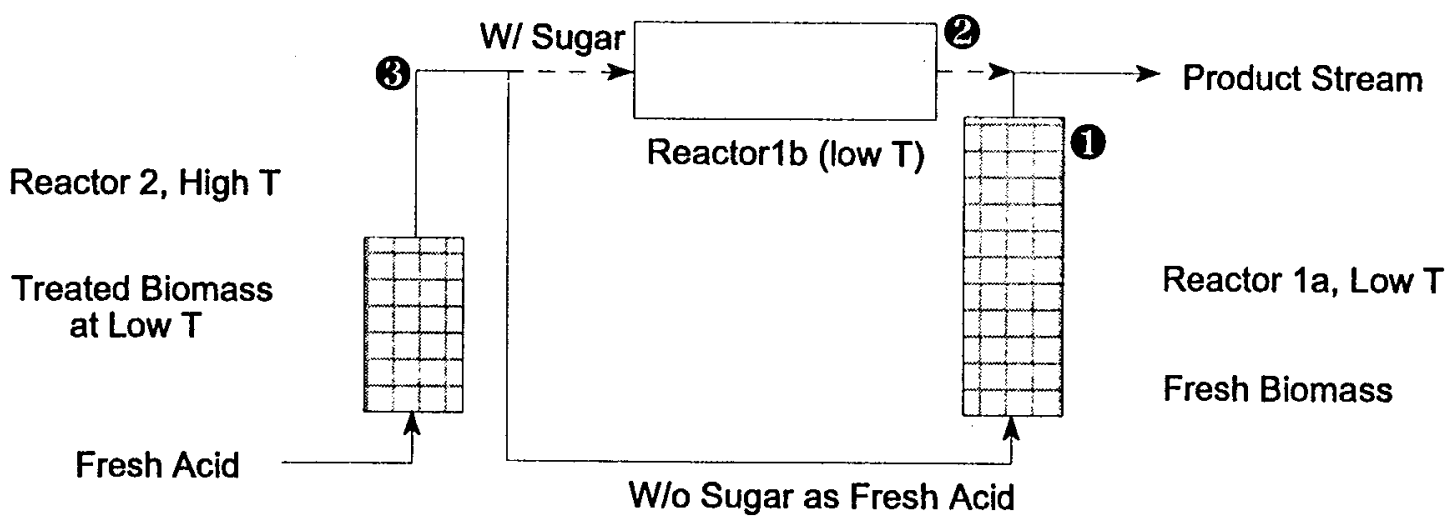

Figure 3. Schematics of temperature step-change, two-stage reverse flow and shrinking bed operation 


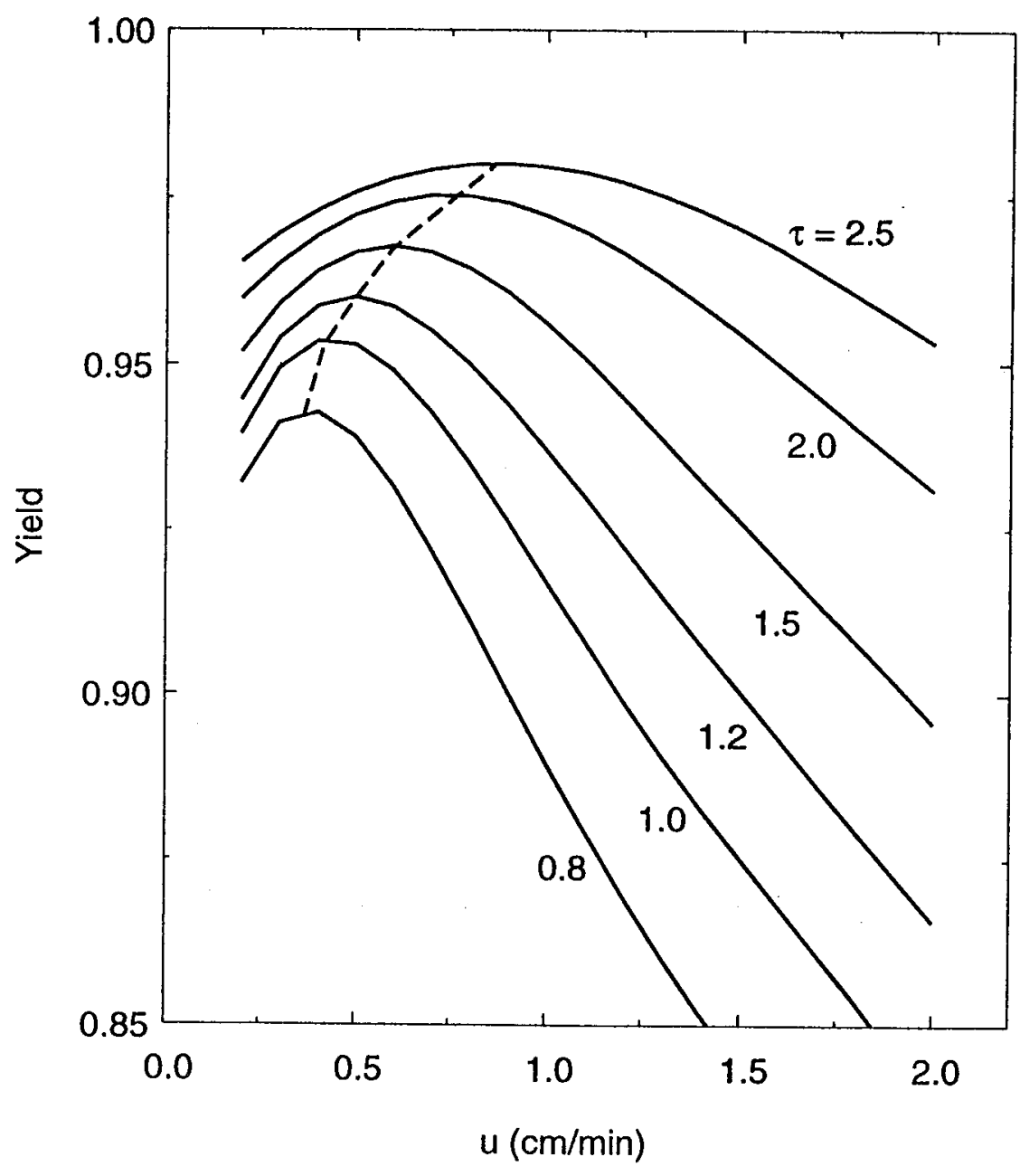

Figure 4. Yield vs. acid flow rate (u) at various $\tau$ values

(two-stage reverse-flow, shrinking bed mode, $\mathrm{T} 1=140 \mathrm{C}, \mathrm{T} 2=170 \mathrm{C}$, $\mathrm{LO}=15.24 \mathrm{~cm}, \mathrm{Co}=3.333 \mathrm{w} / \mathrm{v} \%$, and acid conc. $=0.8 \%$ ) 
optimum $u$ to obtain the maximum yield. For $\tau=0.8$, maximum yield of 0.94 is obtained at $u=$ $0.4 \mathrm{~cm} / \mathrm{min}$, whereas $\tau=2.5$, the maximum yield of 0.98 is obtained at $u=0.8$. High $\tau$ value gives a high sugar yield. However, high $\tau$ will lowers the sugar concentration in the hydrolyzate as clearly shown in Figure 5. With application of respective optimum flow rates, the maximum sugar concentration are seen to be $7.8 \%$ at $\tau=0.8$ and $2.6 \%$ at $\tau=2.5$. Obviously there is a trade-off between the yield and the sugar concentration. A proper choice of $\tau$ can only be made from consideration of the overall process economics.

\section{Comparison between shrinking-bed and non-shrinking- bed operations}

One of the advantages of shrinking bed operation over non-shrinking one is that $\tau$ value becomes higher for shrinking bed than non-shrinking one even for the same amount of liquid throughput. Let us consider a shrinking bed reactor with an initial volume same as that of a nonshrinking bed reactor. For $\tau=1$, this means one reactor volume of liquid has flown through the non-shrink bed reactor during the reaction. For the shrinking bed operation, one reactor volume of liquid based on the initial phase of the reaction, may become two reactor volume at the latter phase if $50 \%$ of solid biomass is dissolved (half of the reactor volume rernaining). Since yield increases with $\tau$ (fluid input into the reactor) at a given temperature and flow rate, the shrinking bed operation is expected to give a higher yield. Figure 6 shows the comparisons between shrinking bed operation and non-shrinking bed, both with temperature step-change reverse-flow operation, and uniform temperature operations. It is seen that shrinking bed operation gives highest sugar yield for a given $\tau$. The sugar yield increases about $5 \%$ at $\tau=1.0,2 \%$ at $\tau=1.5$, and $0.2 \%$ at $\tau=3.0$ over those from non-shrinking bed, step-change reverse-flow operation 


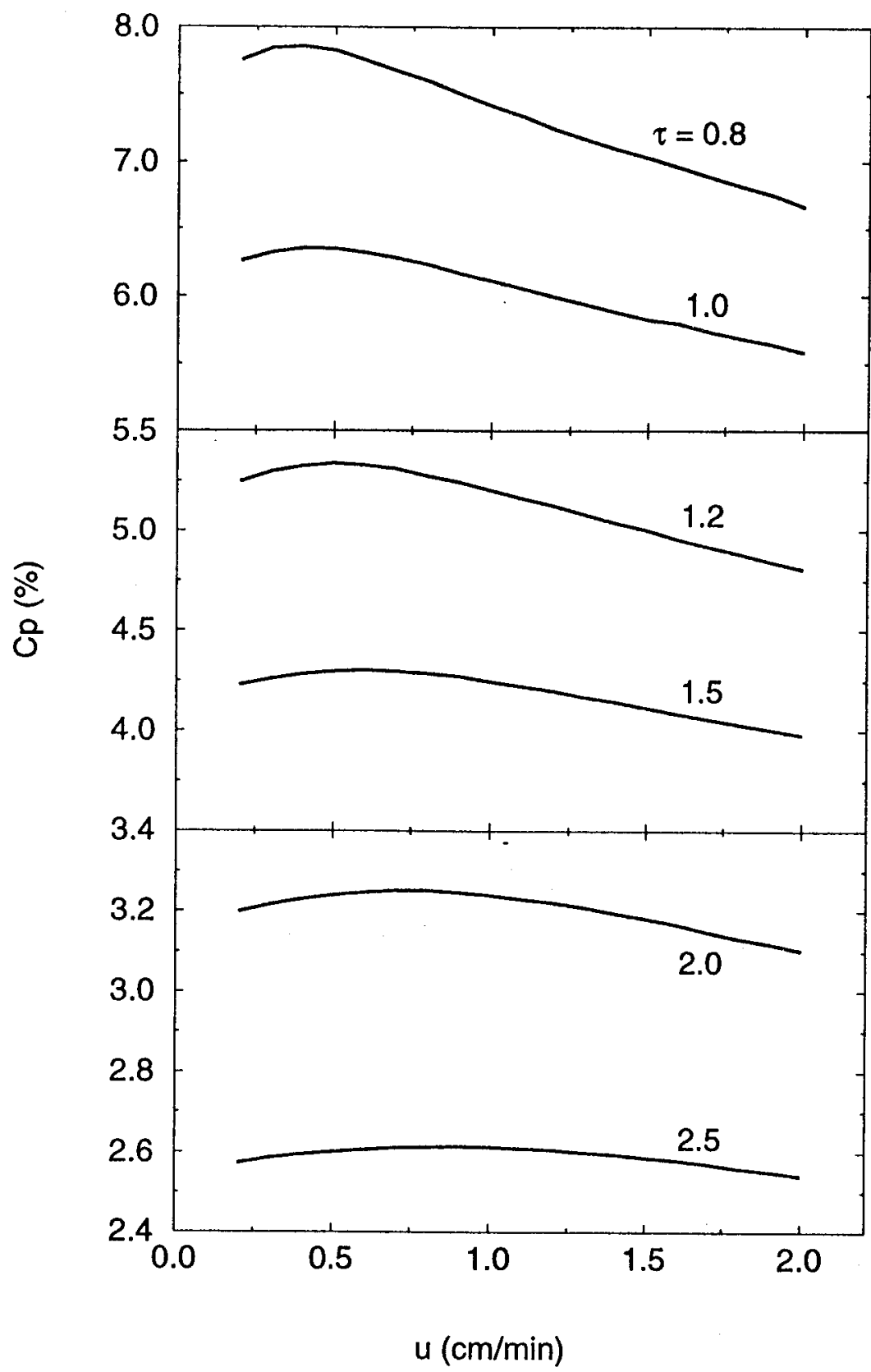

Figure 5. Sugar product conc. (Cp) vs. acid flow rate (u) at various $\tau$ values (two-stage reverse-flow, shrinking bed mode, $\mathrm{T} 1=140 \mathrm{C}, \mathrm{T} 2=170 \mathrm{C}$, $\mathrm{LO}=15.24 \mathrm{~cm}, \mathrm{Co}=3.333$, and acid conc. $=0.8 \%$ ) 


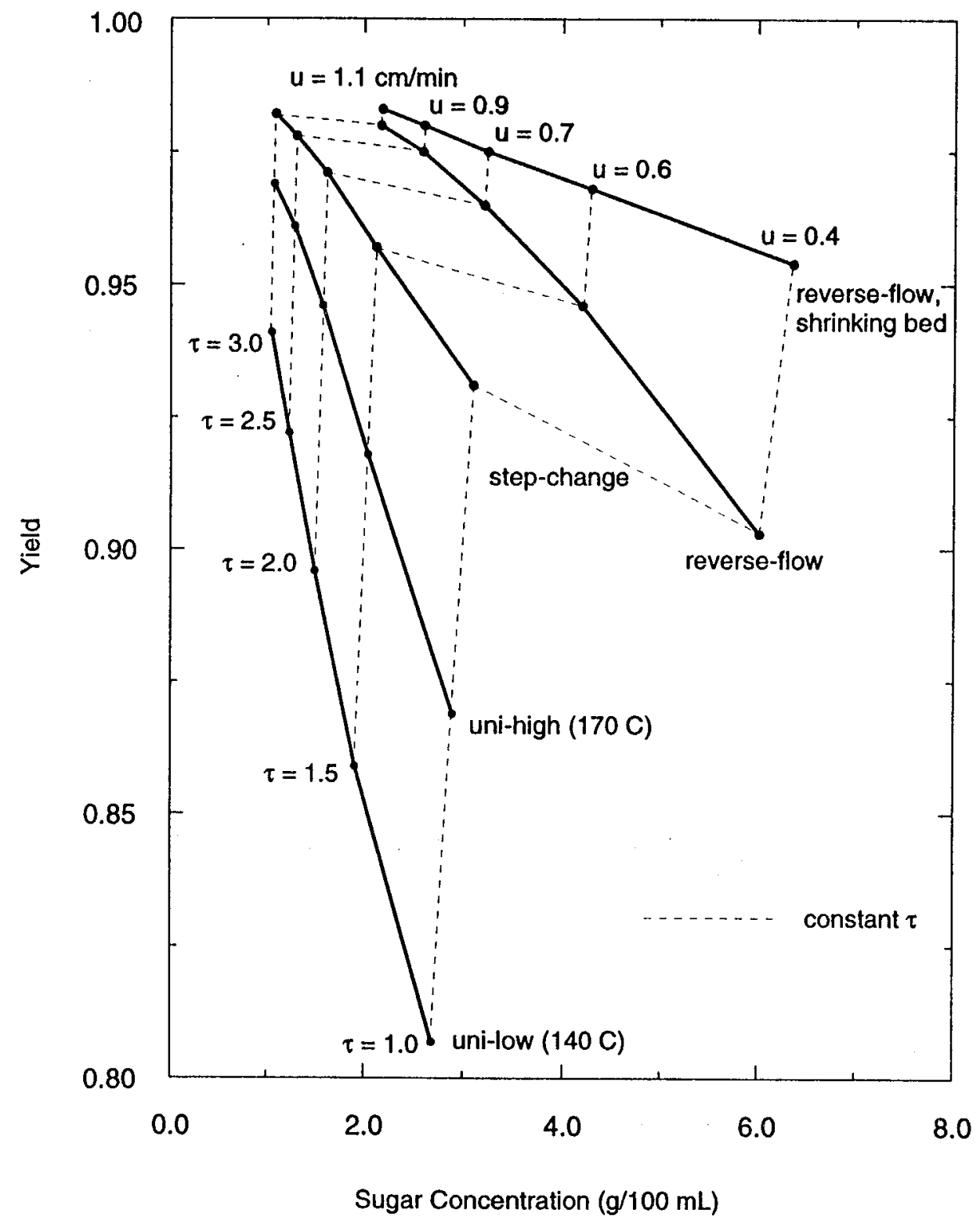

Figure 6. Yield vs. Sugar product concentration under various operation modes (acid conc. $=0.8 \%, \mathrm{Co}=3.333 \mathrm{w} / \mathrm{v} \%, \mathrm{u}=$ optimum values for shrinking bed operation) 
modes. The sugar concentration from the shrinking bed operation is sightly higher than that of non-shrinking bed operation.

\section{Overall hemicellulose conversion}

Figure 7 shows the profile of hemicellulose conversion during a two-stage shrinking bed operation with $\tau=1.5$ for various flow rates. As shown in Figure 4, the flow rates of 0.2 and 2.0 $\mathrm{cm} / \mathrm{min}$ are the lower and upper limits of this work, and flow rate of $0.6 \mathrm{~cm} / \mathrm{min}$ is the optimum value for $\tau=1.5$. Figure 7 indicates that a low flow rate of $0.2 \mathrm{~cm} / \mathrm{min}$ induces an excessive residence time causing over-reaction thus significant decomposition. The reaction achieves near complete conversion at about $\tau=1$. However the sugar yield is about 0.95 and sugar loss about $5 \%$. On the other hand, with the flow rate of $2.0 \mathrm{~cm} / \mathrm{min}$, the hemicellulose conversion is only $91 \%$, and sugar yield is 0.90 . Loss of sugar due to decomposition is therefore about $1 \%$. With the flow rate of 0.6 , the hemicellulose conversion is in excess of $99 \%$, yield is 0.97 , thus causing about $2 \%$ sugar loss. It is also seen that $75 \%$ conversion of hemicellulose was achieved in the first stage alone(low temperature stage).

\section{Distribution of fast and slow portion of hemicellulose during hydrolysis}

A two-stage temperature step-change operation is particularly beneficial for hydrolysis of biphasic hemicellulose. In the overall process scheme, the fast portion of the hemicellulose is hydrolyzed at low temperature and the slow portion of hemicellulose at a high temperature. In our previous kinetic study (5), it was determined that the fast portion of hemicellulose in CCSM is $65 \%$. Figure 8 shows the distribution of fast and slow portions of hemicellulose in the two-stage reactor at optimum temperature step-change $\left(140-170^{\circ} \mathrm{C}\right)$ condition. Three flow rate 


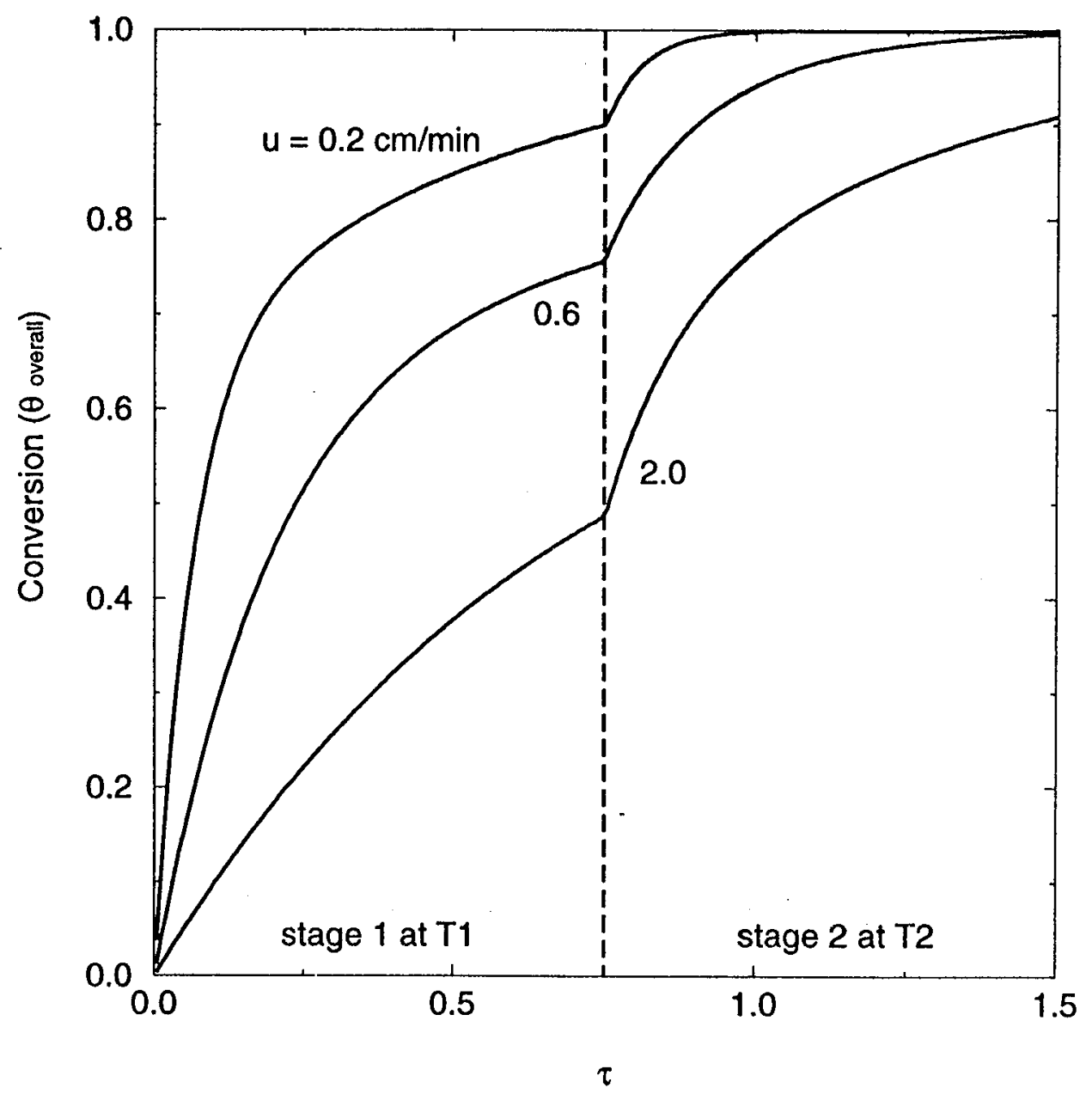

Figure 7. Hemicellulose conversion ( $\theta_{\text {overall) }}$ vs. $\tau$ at various acid flow rate (u) $(\mathrm{T} 1=140 \mathrm{C}, \mathrm{T} 2=170 \mathrm{C}, \mathrm{Lo}=15.24 \mathrm{~cm}, \mathrm{Co}=3.333 \mathrm{w} / \mathrm{v} \%$, and acid conc. $=0.8 \%)$ 


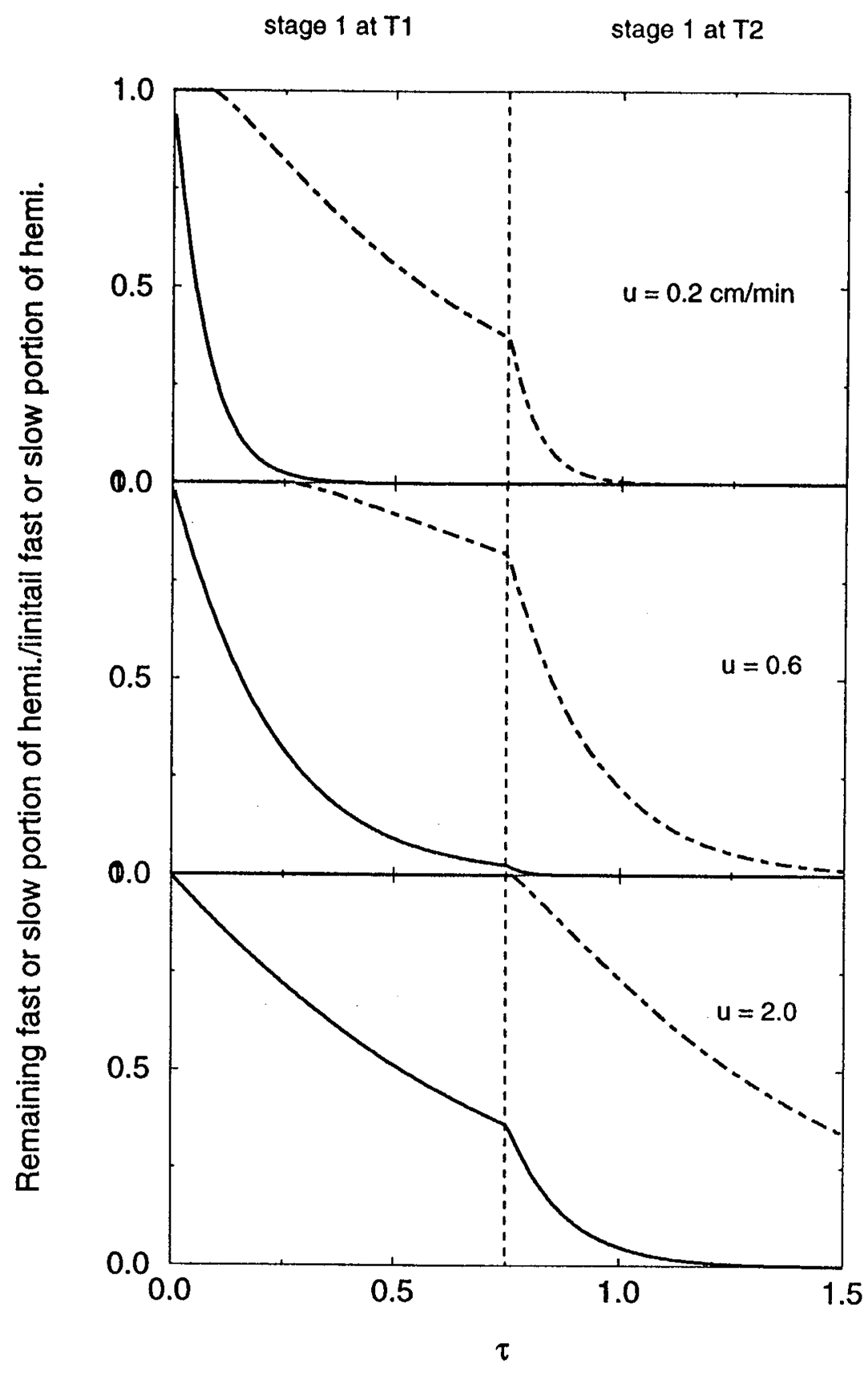

fast portion, - - - - slow portion

Figure 8. Fast or slow portion of hemicellulose vs. $\tau$ at various u values $(\mathrm{T} 1=140 \mathrm{C}, \mathrm{T} 2=170 \mathrm{C}, \mathrm{Lo}=15.24 \mathrm{~cm}, \mathrm{Co}=3.333 \mathrm{w} / \mathrm{v} \%$, and acid conc. $=0.8 \%)$ 
conditions of $0.2,0.6$, and $2.0 \mathrm{~cm} / \mathrm{min}$ at $\tau=1.5$, were applied in the study. For the case of $u=0.2$ $\mathrm{cm} / \mathrm{min}$, fast portion of hemicellulose was quickly dissolved at the early stage, at $\tau$ less than 0.5 , and about $60 \%$ slow portion of hemicellulose was hydrolyzed after first stage. The remaining slow portion of hemicellulose was completely hydrolyzed in the second stage with a final sugar yield of 0.95 . For $u=2.0$, only about $60 \%$ fast portion and no slow portion of hemicellulose were hydrolyzed after the first stage. The remaining fast portion and about $61 \%$ slow portion of hemicellulose were dissolved after the second stage, giving sugar yield of only 0.90 due to incomplete hydrolysis. With $u=0.6$ and $\tau=1.5$ (the optimum point), about $97 \%$ of the fast portion and $19 \%$ of the slow portion of were hydrolyzed after the first stage. The remainder of the fast portion and $99 \%$ of the slow portion of were hydrolyzed after second stage to give the total of $97 \%$ yield.

\section{Bed shrinking during hydrolysis}

In the bed-shrinking model, the shrinking process is terminated when the hydrolysis reaction of hemicellulose is completed. Figure 9 shows the extent of shrinkage for the period of $\tau=1.5$ at various liquid flow rates $(\mathrm{u})$. For the flow rate of $0.2 \mathrm{~cm} / \mathrm{min}$, the shrinking process was terminated at about $\tau=1.0$ due to the completion of the hydrolysis process. The bed shrinkage was $27 \%$ at the completion of the hydrolysis. The shrinkage was about $24 \%$ after the first stage. For the flow rate of $2.0 \mathrm{~cm} / \mathrm{min}$, it is only $13 \%$ after the first stage, and $24 \%$ after second stage. The reaction was not completed after the second stage. At the flow rate of 0.6 $\mathrm{cm} / \mathrm{min}$, the solid bed shrank $20 \%$ after the first stage and to the maximum $27 \%$ after second stage. The reaction was indeed completed at end of second stage. 


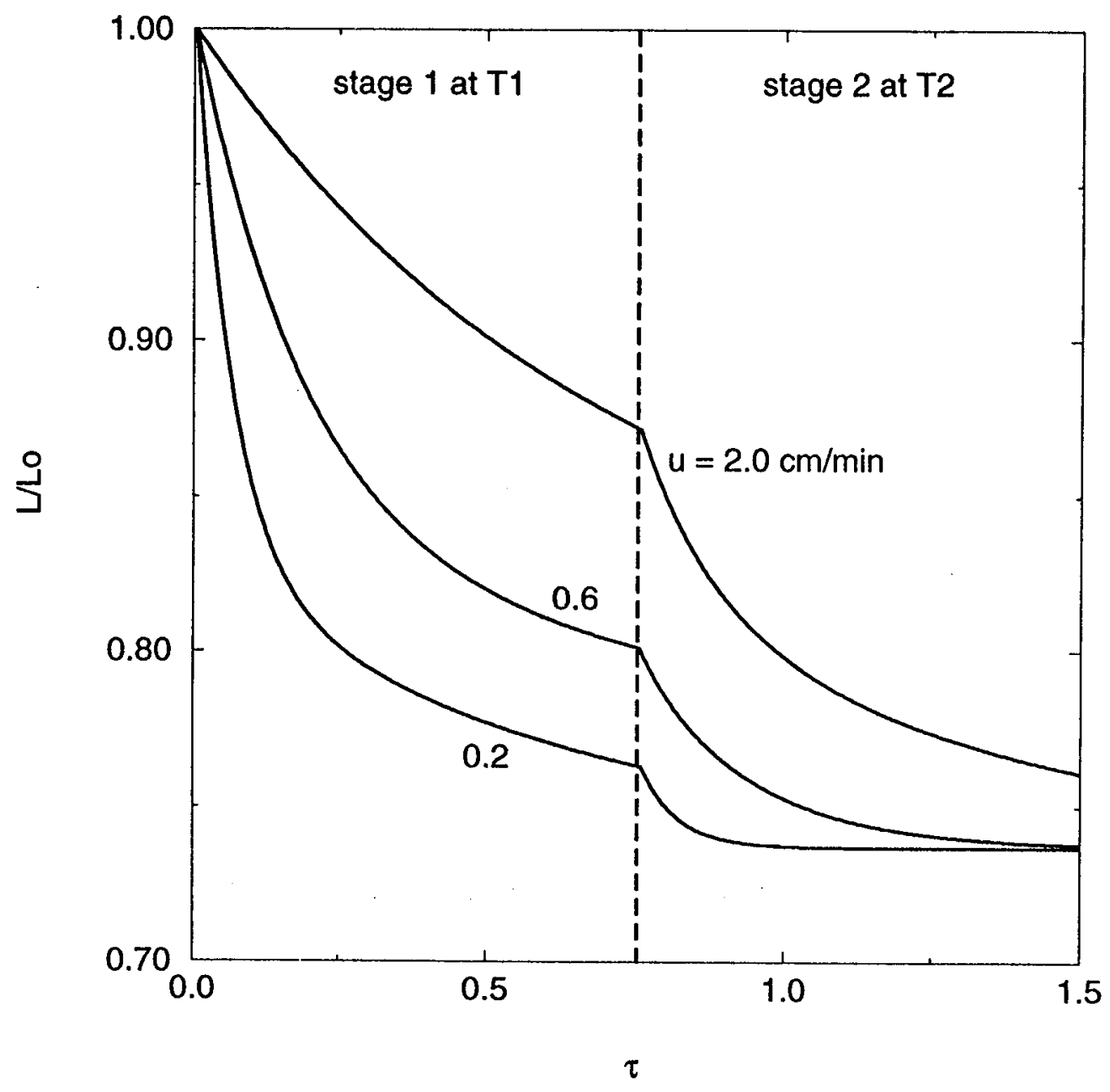

Figure 9. Bed shrinking (L/Lo) vs. $\tau$ at various acid flow rate (u) $(\mathrm{T} 1=140 \mathrm{C}, \mathrm{T} 2=170 \mathrm{C}, \mathrm{Lo}=15.24 \mathrm{~cm}, \mathrm{Co}=3.333 \mathrm{w} / \mathrm{v} \%$, and acid conc.$=0.8 \%)$ 


\section{Analysis of sugar loss during hydrolysis of hemicellulose}

Sugar produced from the hydrolysis of hemicellulose is subject to decomposition. Figures 10 and 11 show how the sugar product is decomposed in each stage. The overall $\tau$ is 1.5 for the two stage operation ( $\tau=0.75$ for each stage). With $u=0.2 \mathrm{~cm} / \mathrm{min}$, about $2.3 \%$ sugar is decomposed in reactor 1a, a reactor packed with fresh biomass at low temperature(refer to Fig. $3 \mathrm{~B}$ for reactors $1 \mathrm{a}, 1 \mathrm{~b}, 2$ ). About $2.7 \%$ sugar is decomposed in reactor 2 , a reactor packed with treated biomass at high temperature. There is only a trace amount of sugar loss from reactor $1 b$, an artificial reactor without solid biomass. For the optimum run of $u=0.6 \mathrm{~cm} / \mathrm{min}$, there is about $2 \%$ sugar loss from reactor 2 , and much less in reactors $1 \mathrm{a}$ and $1 \mathrm{~b}$. The improved performance is attributed to the low temperature condition in reactor $1 \mathrm{a}$. 


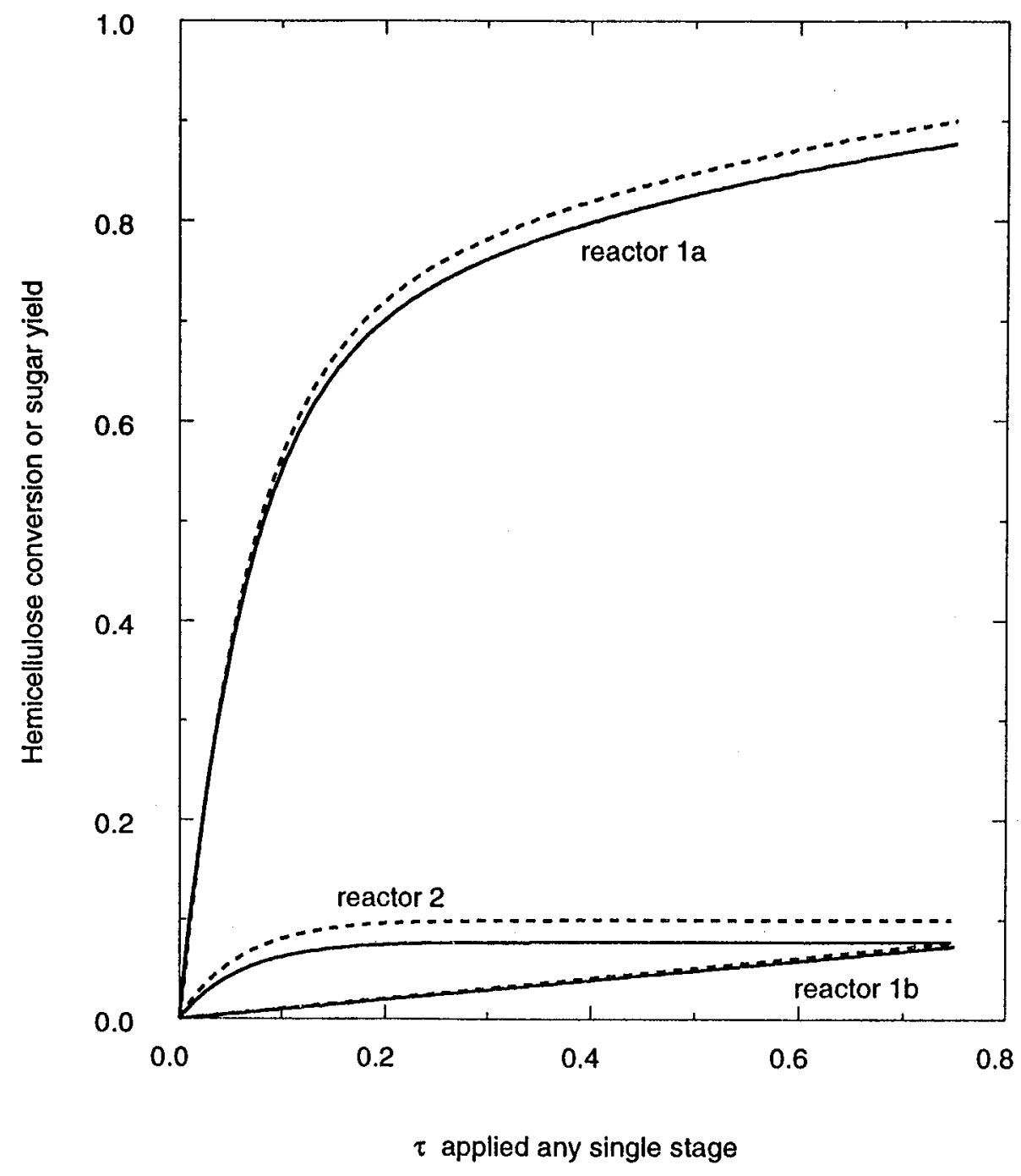

Suagr yield

Hemicellulose conversion

Figure 10. Sugar decomposition at each stage during hydrolysis of hemicellulose $(\mathrm{T} 1=140 \mathrm{C}, \mathrm{T} 2=170 \mathrm{C}, \mathrm{Lo}=15.24 \mathrm{~cm}, \mathrm{Co}=3.333 \mathrm{w} / \mathrm{v} \%, \mathrm{u}=0.2 \mathrm{~cm} / \mathrm{min}$, and acid conc. $=0.8 \%)$ 


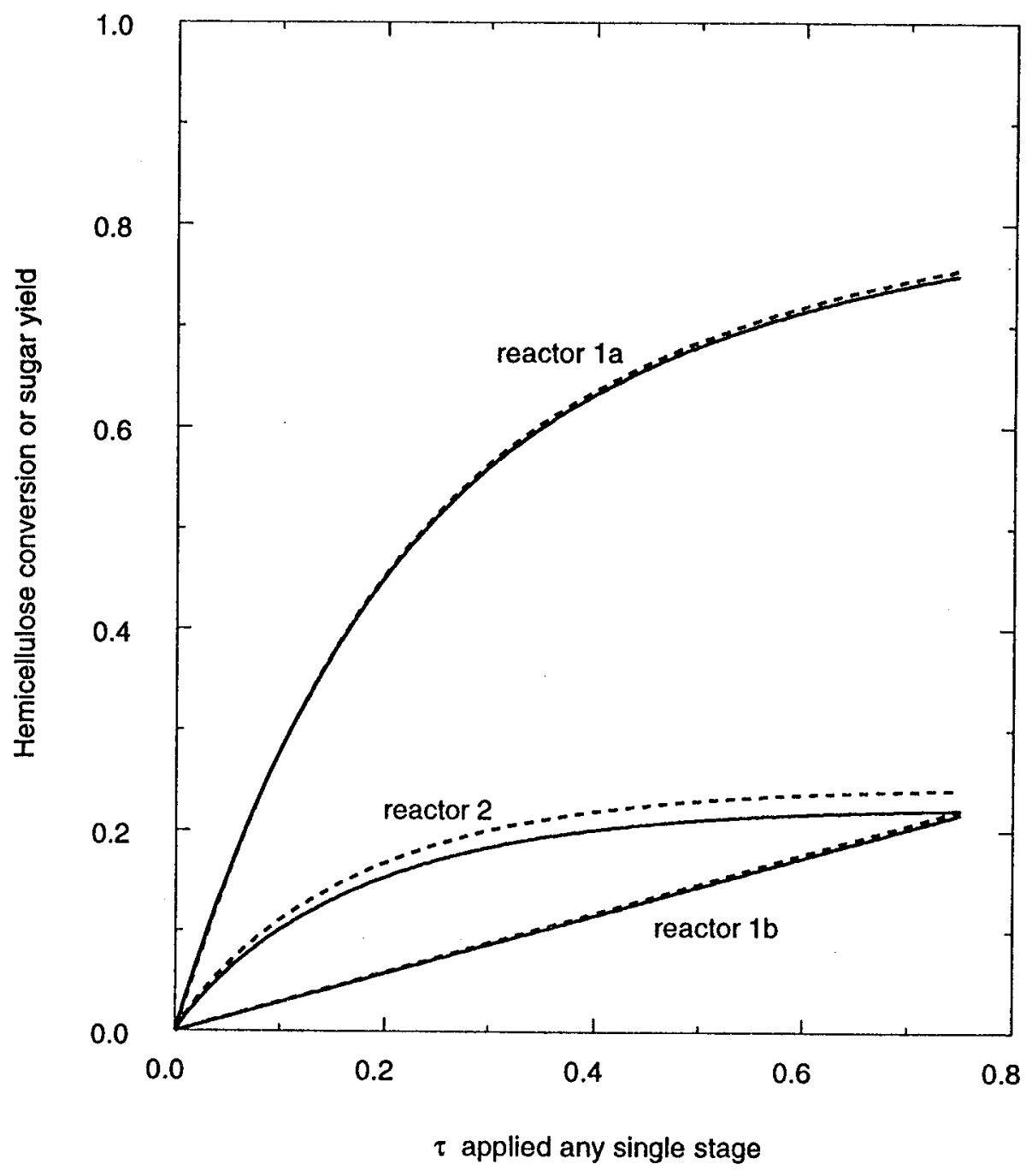

Suagr yield

Hemicellulose conversion

Figure 11. Sugar decomposition at each stage during hydrolysis of hemicellulose $(\mathrm{T} 1=140 \mathrm{C}, \mathrm{T} 2=170 \mathrm{C}, \mathrm{Lo}=15.24 \mathrm{~cm}, \mathrm{Co}=3.333 \mathrm{w} / \mathrm{v} \%, \mathrm{u}=0.8 \mathrm{~cm} / \mathrm{min}$, and acid conc. $=0.8 \%)$ 


\section{CONCLUSIONS}

A modeling and simulation was performed on the shrinking bed, two-stage reverse-flow reactor operating for dilute acid pretreatment of CCSM. The simulation results have shown that the shrinking bed operation increases the sugar yield by about $5 \%$ in comparison to the nonshrinking bed operation at a representative $\tau$ value of 1.0. The flow rate has emerged as an important parameter acutely affecting the performance of the two-stage reactor. A simulated optimal run at $\tau=1.5$ reveals that fast portion of hemicellulose is almost completed hydrolyzed after the first stage reaction. Most of the slow portion of hemicellulose is hydrolyzed in the second stage. The simulation results further proves that the two-stage operation is well suited for hydrolysis of a biphasic substrates including hemicellulose in CCSM. With application of optimum flow rate, the bed shrinkage reached near maximum of $27 \%$ giving almost complete conversion of hemicellulose in CCSM. The corresponding yield was upward of $95 \%$. About three quarters of the total shrinkage occurred after the first stage. Almost all the sugar decomposition occurred at second stage (the high temperature reactor). 


\section{REFERENCES}

1. Lee, Y.Y., Lin, C.M., Johnson, T., and Chambers, R.P. (1978), Biotechnol. Bioeng. Symp. 8, 75-88.

2. Limbaugh, M.L. (1980), MS Thesis, Auburn University, AL.

3. Cahela, D.R., Lee, Y.Y., and Chambers, R.P. (1983), Biotechnol. Bioeng. 25, 3-17.

4. Kim, B.J., Lee, Y.Y., and Torget, R. W. (1993), Appl. Biotechnol. Bioeng. 39, 119-129.

5. Chen, R., Lee, Y.Y., and Torget, R. W. (1996), Appl. Biotechnol. Bioeng. 57/58, 133-146.

6. Torget, R.W., Hayward, T.K., Hatzis, C., and Philippidis, G.P. (1996), Appl. Biotechnol. Bioeng. 57/58, 119-129.

7. Torget, R.W.,Hayward, T. K., and Elander, R. (1997), "Total hydrolysis of lignocellulosic biomass using very dilute acid for ethanol production- a novel continual shrinking bed counter-current reactor design', $19^{\text {th }}$ Symposium on Biotechnology for Fuels $\&$ Chemicals, Colorado Springs, CO.

8. Chen, R. (1997), Ph.D. Dissertation, Auburn University AL 


\section{Task 2: Evaluating Carbonic Acid as a Percolation Pretreatment Agent}

\section{SUMMARY}

The use of carbonic acid as a pretreatment agent has yielded some interesting results. In comparison to sulfuric acid, carbonic acid has been equally effective in separating the cellulose and hemicellulose components. The retention of glucose in the remaining solid and the overall percent solid remaining are higher for the carbonic acid pretreatment than for the sulfuric acid treatment pretreatment. Under optimized conditions, the lignin left in the solid is less for carbonic acid pretreatment than for sulfuric acid pretreatment.

The enzymatic digestibility is slightly higher for the sulfuric acid treated samples than for the carbonic acid treated samples. However, due to the greater percent of original biomass retained in the solid following carbonic acid pretreatment, and the relatively small difference in digestibility, the overall enzymatic digestibility based on original dry biomass reacted is slightly greater for carbonic acid pretreatment than for sulfuric acid pretreatment.

The optimized conditions for the two pretreatment processes differs slightly, in that the carbonic acid pretreatment conditions are slightly more severe. For the carbonic acid pretreatment, the optimized reaction conditions are: low temperature $140-150 \mathrm{C}$, high temperature 190-200 C, reaction time per stage 20 minutes, flow rate $4.0 \mathrm{~mL} / \mathrm{min}$, with a back pressure of $450 \mathrm{psi}$, and a front pressure of $350 \mathrm{psi}$. The previously determined optimized conditions for sulfuric acid pretreatment are: low temperature $150 \mathrm{C}$, high temperature $190 \mathrm{C}$, reaction time per stage 15 minutes, flow rate $4.0 \mathrm{~mL} / \mathrm{min}$, back pressure $350 \mathrm{psi}$. The flow rates and initial low temperatures are relatively the same for the two treatments, whereas the high 
temperature, reaction time, front pressure, and back pressure are greater for the carbonic acid treatment process. Although it requires a slightly greater energy input, the benefits of the carbonic acid pretreatment process, both in increased component separation, especially high degree of lignin solubilization and in easier reagent cleanup and disposal, make carbonic acid pretreatment process a viable alternative pretreatment method for biomass pretreatment.

\section{INTRODUCTION}

Dilute-acid pretreatment is an established pretreatment method and it is highly effective in solubilizing hemicellulose. Sulfuric acid is the most common acid used in the biomass pretreatment. However, using sulfuric acid causes an environmental problem, that is, the disposal of gypsum. The gypsum is formed when limestone is used to neutralize the sulfuric acid in the pretreatment stream. .

Carbonic acid is a weak acid with a pKa of 6.38 (Seen in Table 1), and its solubility in water is $0.16 \mathrm{wt} \%$. At room temperature $\left(20^{\circ} \mathrm{C}\right)$ and ambient pressure, the $\mathrm{pH}$ of the carbonic acid solution is calculated to be 3.90. Under the pressure, the amount of $\mathrm{CO}_{2}$ dissolved in water also increases and the $\mathrm{pH}$ of carbonic acid solution could be lower further. At that level of acidity, The carbonic acid may be acidic enough to initiate the hydrolysis of hemicellulose at elevated temperature, yet, it is less corrosive than sulfuric acid. The carbonic acid is formed by dissolution of carbon dioxide in water. Carbon dioxide is a side product of the fermentation of glucose into ethanol, and thus can be recycled to generate carbonic acid. It is a weak acid which readily dissociates back into carbon dioxide and water. The acid remained in solid and present in the exit streams can be removed simply by vaporization. No post-treatments such as washing 
Table 1. Ka and $\mathrm{pKa}$ values of some weak acids in water at $25^{\circ} \mathrm{C}$

\begin{tabular}{|l|c|c|c|}
\hline Name of acids & Formula & $\mathrm{Ka}$ & $\mathrm{pKa}$ \\
\hline Formic acid & $\mathrm{HCOOH}$ & $1.7 \mathrm{E}-4$ & 3.77 \\
\hline Acetic acid & $\mathrm{H}_{3} \mathrm{CCOOH}$ & $1.8 \mathrm{E}-5$ & 4.74 \\
\hline Carbonic acid & $\mathrm{H}_{2} \mathrm{CO}_{3}$ & $4.2 \mathrm{E}-7$ & 6.38 \\
hydrogen carbonate ion & $\mathrm{HCO}_{3}^{-}$ & $4.8 \mathrm{E}-11$ & 10.32 \\
\hline Phosphoric acid & $\mathrm{H}_{3} \mathrm{PO}_{4}$ & $7.5 \mathrm{E}-3$ & 2.12 \\
Dihydrogen phosphate ion & $\mathrm{H}_{2} \mathrm{PO}_{4}^{-}$ & $6.2 \mathrm{E}-8$ & 7.21 \\
Hydrogen phosphate ion & $\mathrm{HPO}_{4}^{2-}$ & $4.8 \mathrm{E}-13$ & 13.32 \\
\hline
\end{tabular}


and neutralization are needed. Carbonic acid based pretreatment therefore has the potential to be an ecomomical, clean, and environmentally benign method for biomass pretreatment.

Another important feature of carbonic acid as an acidic pretreatment agent is its buffer property. Because carbonic acid is diprotic, there are two different buffer systems, that is, $\mathrm{HCO}_{3}{ }^{-}$ $/ \mathrm{H}_{2} \mathrm{CO}_{3}$ and $\mathrm{CO}_{3}^{-} / \mathrm{HCO}_{3}^{-}$. Bicarbonate ion $\mathrm{HCO}_{3}{ }^{-}$acts as the conjugate base of the first system and the acid of the second. The distribution curve of carbonic acid is shown in Figure 12. Its buffering capacity clearly functions over quite different $\mathrm{pH}$ regions. The buffering capability of carbonic acid may play an important role in the pretreatment. At the initial phase of the pretreatment, carbonic acid dissociates and forms hydrogen ion to promote the hydrolysis of hemicellulose. When the acidic component of the hemicellulose fraction dissolves in the solution and increase the acidity of solution, the carbonic acid buffer can neutralize an appreciable amount of formed acids and keep $\mathrm{pH}$ relatively constant. Consequently, it minimizes the sugar decomposition.

The purpose of this study is to evaluate carbonic acid as an acidic pretreatment agent. Process factors such as reaction temperature, time, presoaking etc. were investigated. The pretreatment effectiveness was evaluated based the extent of solubilization of hemicellulose and retention of glucan in solid residue.

\section{MATERIALS/METHODS}

\section{Materials}

Dry yellow poplar feedstock milled and screened to 10-40 mesh was supplied by the National Renewable Energy Laboratory (NREL) and used as the lignocellulosic substrate. There was slight variation in the composition, as determined by NREL Standard Procedures, of the 


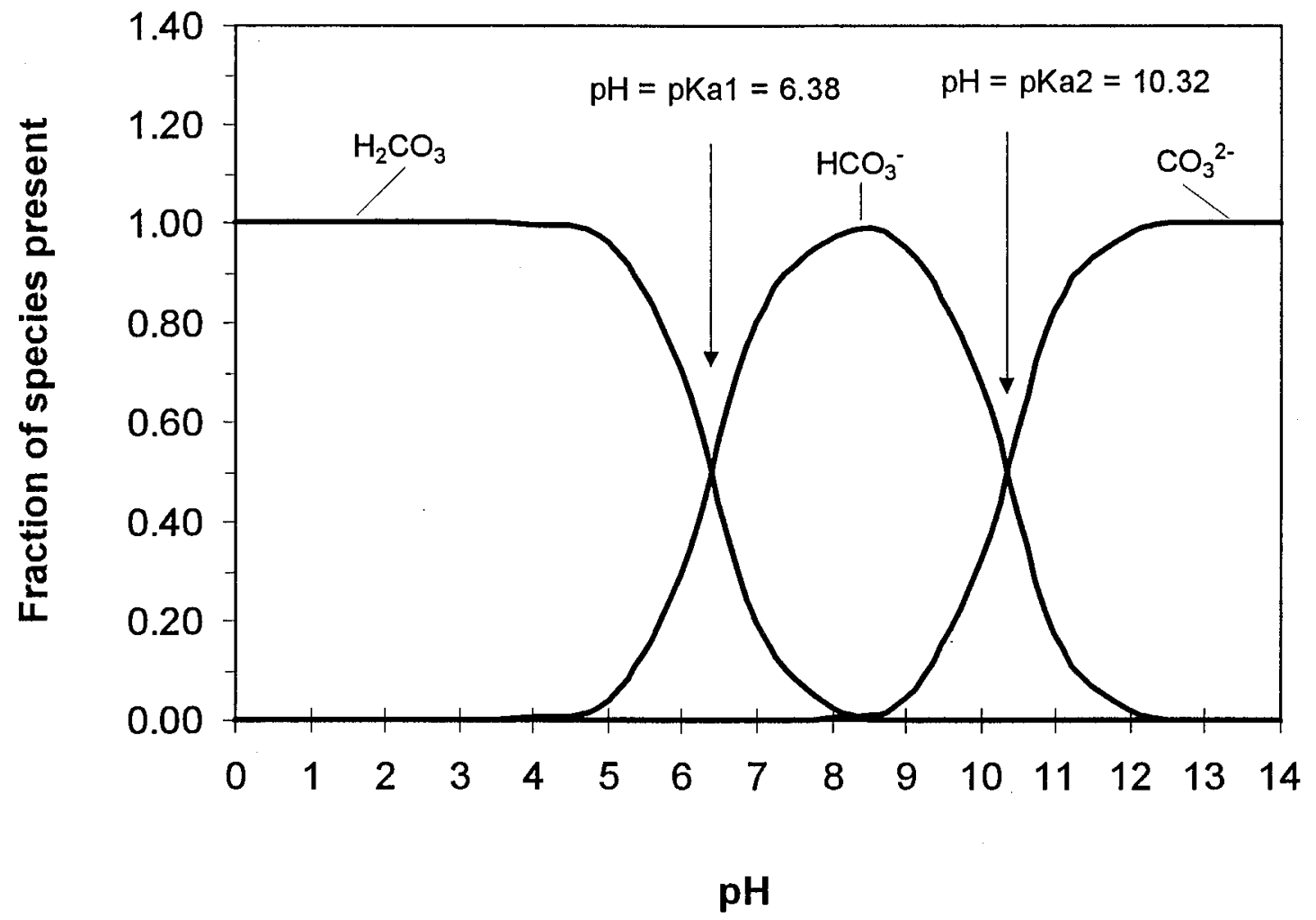

Figure 12. Distribution curves for carbonic acid and bicarbonate ion as a function of $\mathrm{PH}$. At any $\mathrm{pH}$, there are only two predominant spcies $\left(\mathrm{H}_{2} \mathrm{CO}_{3}\right.$ and $\mathrm{HCO}_{3}{ }^{-}$or $\mathrm{HCO}_{3}{ }^{-}$and $\left.\mathrm{CO}_{3}{ }^{2-}\right)$ present in solution. When $\left[\mathrm{H}_{2} \mathrm{CO}_{3}\right]=\left[\mathrm{HCO}_{3}^{-}\right], \mathrm{pH}=\mathrm{pka}=6.38$. When $\left[\mathrm{HCO}_{3}{ }^{-}\right]=\left[\mathrm{CO}_{3}{ }^{2-}\right], \mathrm{pH}=\mathrm{pKa} 2=$ 10.32 . 
individual lots of feedstock and therefore composition based on original oven dry weight is noted on the tables where relevant. The cellulase enzyme, Spezyme-CP, Lot No. 41-95034-004, was obtained from Environmental Biotechnologies, Inc., Menlo Park, CA. The specific activity of the enzyme as determined by the supplier is as follows: Filter paper activity $=64.5 \mathrm{FPU} / \mathrm{mL}, \beta-$ glucosidase activity $=57.6 \mathrm{p}-\mathrm{NPGU} / \mathrm{mL}$. Birch wood xylan (Sigma) was used in hydrolysis experiment.

\section{Experimental Setup and Operation}

The system consists of stock solution reservoir, pump, programmable drying oven, reactor, and liquid holding tank which also served as a back pressure vessel. Pretreatment agents and water solutions were pumped sequentially by a duplex metering pump (LDC mini-pump) to a packed-bed reactor through a preheating coil. The flow rate of solution was monitored by flowmeter and water solution by a buret. The reactor was constructed out of SS 316 tubing, to the dimension of $5 / 8$ " OD x 6" L ( $33 \mathrm{~cm}^{3}$ of internal volume). The reactor temperature was controlled in a temperature programmable oven. An autoclave $(600 \mathrm{~mL}$, Parr Instrument) was used as a liquid holding tank to which a nitrogen cylinder was connected to apply back pressure preventing evaporation of reactant fluid. In a DA experiment, $10 \mathrm{~g}$ of undried biomass sample was packed into the reactor and prewet with acid solution. At the completion of a run the reactor was pumped with water to remove the residual sugar and acid trapped in the treated biomass. 2The effluent collected in the holding tank was filtered and analyzed for composition. The wet solids discharged from the reactor were separated into two portions. One was oven dried at $105^{\circ} \mathrm{C}$ overnight for measurement of weight loss and further subjected to composition analysis, the other was used in the enzymatic digestibility test.

For the pretreatment with carbonic acid a pressurized carbonic acid generator was added to the systemm.. 
The carbonic acid generator consists of a $400 \mathrm{ml}$ stainless steel autoclave vessel, used as a mixing chamber. The vessel is initially charged with $350 \mathrm{~mL}$ DI HO. Carbon dioxide is introduced to the base of the chamberfrom a $\mathrm{COO} 2$ cyclinder. The $\mathrm{CO} 2$ is allowed to escape to purge the system of initial air trapped inside before the system was closed. The system was maintained with high agitation in order to promote gas/liquid mass transfer and to attain equilibrium. An exit stream was connected between the chamber and the percolation pump so as to allow for the transfer of the newly generated carbonic acid under high pressure.

\section{Digestibility Test}

Enzymatic hydrolysis of pretreated substrates was performed in $250 \mathrm{~mL}$ glass bottles at $50^{\circ} \mathrm{C}, \mathrm{pH} 4.8$, with a glucan loading of $1 \%(\mathrm{w} / \mathrm{v})$. It was agitated at $150 \mathrm{rpm}$ on a Shaker Incubator. The enzyme loading of 60 IFPU/g glucan was applied. The enzymatic digestibility is defined as (total amount of glucose released) x $0.9 /$ total glucan. A dehydration factor of 0.9 is used to convert the glucose to glucan.

\section{Analytical Methods}

The biomass samples were analyzed for sugar and lignin content following the procedure described in NREL-CAT Standard Procedures (No. 002-005 and LAP 010). Bio-Rad Aminex HPX-87H and HPX-87P HPLC columns were used for analysis of sugars and decomposition products. The sugar content in liquid sample was determined after the liquid sample was subjected to a secondary acid hydrolysis. The conditions in the secondary hydrolysis were: $4 \mathrm{wt} \%$ sulfuric acid, $121^{\circ} \mathrm{C}$, and 1 hour. 


\section{RESULTS AND DISCUSSION}

\section{Carbonic Acid $\left(\mathrm{H}_{2} \mathrm{CO}_{3}\right)$ as a Pretreatment Reagent}

The formation of carbonic acid from $\mathrm{DI}_{2} \mathrm{O}$ and $\mathrm{CO}_{2}$ was first investigated. Using the setup and operation noted above, experiments were carried out to determine the acidity and stability of carbonic acid. The results are shown in Table 2. The change of $\mathrm{pH}$ over $150-400 \mathrm{psi}$ was within 3.4-3.7. At pressures greater than $200 \mathrm{psi}$, the $\mathrm{pH}$ is independent of the pressure staying at near 3.5. The lowest $\mathrm{pH}$ generated was $\mathrm{pH} 3.4$ at 300 psi. At room temperature and ambient pressure the carbonic acid maintained its $\mathrm{pH}$ for a period in excess of 24 hours, much longer than the reaction time needed

\section{Effect of presoaking}

Presoaking of substrates is usually carried out in most of the kinetic experiments since it can eliminate the transient behavior in the reaction process. However, it is a process incurring additional cost. We were interested in verifying the effect of presoaking in normal percolation reactor operation. The presoaking was carried out under atmospheric pressure at room temperature using yellow poplar feedstock. Presoaking times ranged from 0 to 15.25 hours. The pretreatment was carried out at $180 \mathrm{C}, 0.05 \mathrm{wt} \% \mathrm{H}_{2} \mathrm{SO}_{4}$ and 350 psi back pressure with a flow rate of $4 \mathrm{~mL} / \mathrm{min}$. The results showed that presoaking has a negligible effect within this experimental range (Table 3). There was only a slight decrease in the percent glucan removed. The XMG removed and Klason Lignin remaining were unaffected. Presoaking had no effect on the degree of separation between glucan and XMG under these conditions.

\section{Effect of pumping}

Pumping of liquid during preheating period of percolation reaction is a factor influencing the concentration of the sugar product and the cost of acid. Percolation experiments were thus 
Table 2. Relationship Between Carbon Dioxide Pressure and the $\mathrm{pH}$ of the Carbonic Acid formed

\begin{tabular}{cc}
$\begin{array}{c}\text { Pressure of } \\
\text { Carbon Dioxide (psi) }\end{array}$ & $\begin{array}{c}\text { pH of } \\
\text { Carbonic Acid }\end{array}$ \\
\hline 150 & 3.7 \\
200 & 3.5 \\
300 & 3.4 \\
350 & 3.5 \\
400 & 3.5 \\
\hline
\end{tabular}

Temperature: $25 \mathrm{C}$

Reaction volume: $350 \mathrm{~mL}$ water, $400 \mathrm{~mL}$ chamber 


\section{Table 3. Effect of Presoaking Time on Dilute-Acid Pretreatment}

\section{of Hybrid Poplar Feedstock}

Pretreatment conditions: 0.05 wt\% Sulfuric Acid, $180 \mathrm{C}, 20 \mathrm{~min}$, flow rate $4 \mathrm{~mL} / \mathrm{min}, 350$ psi backpressure Presoak at room temperature, 1 ATM

\begin{tabular}{|c|c|c|c|c|c|c|c|c|}
\hline \multirow{2}{*}{$\begin{array}{l}\text { Presoak } \\
\text { Time (hr) }\end{array}$} & \multirow{2}{*}{$\begin{array}{l}\% \text { Solid } \\
\text { Remaining }\end{array}$} & \multicolumn{3}{|c|}{ \%Glucan } & \multicolumn{3}{|c|}{$\% X M G$} & \multirow{2}{*}{$\frac{\% \text { Lignin }}{\text { Klason }}$} \\
\hline & & Solid & Liquid & Total & Solid & Liquid & Total & \\
\hline untreated & 100.00 & 43.00 & N/A & 43.00 & 18.52 & $N / A$ & 18.52 & 26.73 \\
\hline 0.00 & 59.50 & 40.19 & 2.56 & 42.75 & 3.54 & 13.96 & 17.50 & 16.08 \\
\hline 2.00 & 57.75 & 40.11 & 2.81 & 42.92 & 3.27 & 14.34 & 17.61 & 16.68 \\
\hline 15.25 & 58.40 & 38.35 & 3.08 & 41.43 & 3.38 & 14.71 & 18.09 & 16.82 \\
\hline
\end{tabular}

Note: all sugars and lignin content in the table based on oven-dry untreated biomass.

XMG: the total Xylan, Mannan, and Galactan

N/A: Not Applicable 
carried out: one with constant pumping during the preheating phase and the other with pumping only after the reaction temperature was reached. The constant pumping cuased decrease in the percent solid remaining (Table 4). The percent glucan content and the percent Klason lignin in the solid were slightly lower with constant pumping, whereas the percent XMG removed was unaffected by pumping mode. This indicates that the reaction times selected were sufficient for solubilizing the hemicellulose. For the interest of reducing the input of the pretreatment reagent and retaining high concentration of the product, we conclude that it is highly desirable to go with the pump off mode during preheating in normal operation of a percolation reactor.

\section{Carbonic Acid Pretreatment (ambient front pressure)}

The effect of pretreatment reagent was investigated using the yellow poplar as the feedstock. Pretreatment conditions of $180^{\circ} \mathrm{C}, 20$ minutes, $4 \mathrm{~mL} / \mathrm{min}$ flow rate, and $350 \mathrm{psi}$ of back pressure were applied. The pretreatment reagents were $0.05 \mathrm{wt} \% \mathrm{H}_{2} \mathrm{SO}_{4}$, deionized $\mathrm{H}_{2} \mathrm{O}$, and carbonic acid $\left(\mathrm{H}_{2} \mathrm{CO}_{3}\right.$ ). The carbonic acids used were of $\mathrm{pH} 3.7$, (formed under $150 \mathrm{psi}$ ) and $\mathrm{pH} 3.4$ (formed under $300 \mathrm{psi}$ ). The carbonic acid has displayed the ability to maintain its $\mathrm{pH}$ for a period of at least 24 hours. Therefore our initial trials were conducted with a separate carbonic acid generator not connected to the percolation system. Once the acid was formed it was introduced to the percolation system from storage reservoirs at ambient pressure, in the same manner sulfuric acid and water are introduced. The $\mathrm{pH}$ was monitored before and after the reaction to insure that there wasn't significant acid dissociation. In all cases the $\mathrm{pH}$ of the intake acid was the same before and after the percolation process, thus indicating that if any dissociation takes place it must happen when the temperatures and pressures are higher, after the acid is introduced into the system. Preliminary results (Table 5) have shown carbonic acid (Runs \#3 and \#4) to react in much the same way as water (Run \#2). For both reagents the percent glucan remaining was $47 \%$ (based on dry weight of untreated biomass). This is equal to almost $100 \%$ of 


\section{Table 4. Effect of Constant Pretreatment Agent Pumping During Heating}

on the Solid Content of Yellow Poplar Feedstock

Pretreatment conditions: $0.05 \mathrm{wt} \%$ Sulfuric Acid, $180 \mathrm{C}, 20 \mathrm{~min}$, flow rate $4 \mathrm{~mL} / \mathrm{min}$, 350 psi back pressure

\begin{tabular}{lccccc}
$\begin{array}{c}\text { Pump Stage } \\
\text { During Heating }\end{array}$ & $\mathrm{pH}$ & $\begin{array}{c}\text { \% Solid } \\
\text { Remaining }\end{array}$ & \% Glucan & $\%$ XMG & $\begin{array}{c}\text { \% Klason } \\
\text { Lignin }\end{array}$ \\
\hline Untreated & & 100.00 & 46.72 & 18.62 & 26.73 \\
Pump On & 2.0 & 59.36 & 42.21 & 2.73 & 14.64 \\
Pump Off & 2.0 & 64.45 & 44.78 & 2.72 & 16.38 \\
\hline
\end{tabular}

Note: all sugars and lignin content in the table based on oven-dry untreated biomass. XMG: the total Xylan, Mannan, and Galactan 


\section{Table 5. Effect of Pretreatment Agent on Solid Content of Yellow Poplar Feedstock}

Pretreatment conditions: $180 \mathrm{C}, 20 \mathrm{~min}$, flow rate $4 \mathrm{~mL} / \mathrm{min}, 350$ psi backpressure

\begin{tabular}{|c|c|c|c|c|c|c|c|}
\hline $\begin{array}{l}\text { Run } \\
\text { No. }\end{array}$ & $\begin{array}{l}\text { Pretreatment } \\
\text { Solvent }\end{array}$ & $\begin{array}{c}\text { initial } \\
\mathrm{pH}\end{array}$ & $\begin{array}{c}\text { final } \\
\mathrm{pH}\end{array}$ & $\begin{array}{l}\% \text { Solid } \\
\text { Remaining }\end{array}$ & $\begin{array}{l}\text { \% Glucan } \\
\text { Remaining }\end{array}$ & $\begin{array}{l}\% \text { XMG } \\
\text { Remaining }\end{array}$ & $\begin{array}{l}\% \text { K Lignin } \\
\text { Remaining }\end{array}$ \\
\hline & untreated & & & 100.00 & 46.72 & 18.62 & 26.73 \\
\hline 1 & 0.05 wt $\%$ Sulfufic Acid & 2.0 & 2.3 & 59.36 & 42.21 & 2.73 & 14.64 \\
\hline 2 & Water & 5.1 & 3.0 & 64.28 & 46.99 & 5.23 & 13.54 \\
\hline 3 & Carbonic Acid & 3.7 & 3.3 & 62.87 & 44.73 & 6.82 & 14.81 \\
\hline 4 & Carbonic Acid & 3.4 & 3.1 & 72.59 & 46.72 & 7.26 & 14.82 \\
\hline
\end{tabular}

Note: all sugars and lignin content in the table based on oven-dry untreated biomass.

XMG: the total Xylan, Mannan, and Galactan 
the original glucan present. The percent XMG removed was between 65 and $70 \%$. Sulfuric acid treatment yielded only $42.21 \%$ glucan remaining in the solid, or equivalent to $90 \%$ of original glucan, and removed $86 \%$ of the original XMG. All four reagents removed about half of the Klason Lignin. It appeared that the $\mathrm{pH}$ difference of 3.4 to 3.7 was insufficient to cause significant difference in the pretreatment effect. While $\mathrm{H}_{2} \mathrm{O}$ and $\mathrm{H}_{2} \mathrm{CO}_{3}$ removed less glucan, they were also less effective in removing the XMG.

The lowest $\mathrm{pH}$ obtained from our attempts to form $\mathrm{H}_{2} \mathrm{CO}_{3}$ was 3.4. For this agent there was a glucan content of $46.72 \%$ in the remaining solid indicating that nearly $100 \%$ of the original glucan was left intact. Overall there was little difference between the results from carbonic acid at $\mathrm{pH} 3.7$ and $\mathrm{pH} 3.4$ in terms of XMG and Klason lignin removal. The carbonic acids at both $\mathrm{pHs}$ reacted similarly to the way $\mathrm{H}_{2} \mathrm{O}$ reacted. In terms of XMG removal, $\mathrm{H}_{2} \mathrm{SO}_{4}$ was far superior to carbonic acid or $\mathrm{H}_{2} \mathrm{O}$. These results again raised the question of acid dissociation. Since in the pretreatment results the carbonic acid appears to behave much as water, it is quite possible that at the high temperatures of the reaction, the carbonic acid dissociates back to carbon dioxide and water. Since the output stream is a blend of acids, (acetic acid, formic acid, carbonic acid, etc...) it difficult to accurately determine what portion of the acidity of the exit stream is due to the input acid and what portion is due to the side products.

\section{Carbonic Acid Pretreatment (front and back pressure)}

To overcome this uncertainty, the ensuing study focused on confirming whether the acid can be an effective agent. Table 6 presents an overview of a wide range of possible conditions. Runs 1-4 are our aforementioned data presented again as references. These previous runs showed carbonic acid to have little to no effect on the samples. The remaining runs were conducted with the input carbonic acid under 350 psi front pressure and a back pressure on the system of 450 psi. For these runs the carbonic acid generator was connected directly to the percolation pump, and the generated acid was held at a high pressure until needed. This pressurized system is intended 
Table 6. Effect of Pretreatment Agent on Solid Content of Yellow Poplar Feedstock

\begin{tabular}{|c|c|c|c|c|c|c|}
\hline $\begin{array}{l}\text { Run } \\
\text { No. }\end{array}$ & $\begin{array}{l}\text { Pretreatment } \\
\text { Solvent }\end{array}$ & $\begin{array}{l}\text { initial } \\
\mathrm{pH}\end{array}$ & $\begin{array}{c}\% \text { Solid } \\
\text { Remaining }\end{array}$ & $\begin{array}{l}\% \text { Glucan } \\
\text { Remaining }\end{array}$ & $\begin{array}{c}\% \text { XMG } \\
\text { Remaining }\end{array}$ & $\begin{array}{l}\% \mathrm{~K} \text { Lignin } \\
\text { Remaining }\end{array}$ \\
\hline & Untreated & & 100.00 & 46.72 & 15.78 & 22.90 \\
\hline $1^{*}$ & 0.05 wt $\%$ Sulfuric Acid & 2.0 & 59.36 & 42.21 & 2.73 & 14.64 \\
\hline $2^{*}$ & Water & 5.1 & 64.28 & 46.99 & 5.23 & 13.54 \\
\hline \multicolumn{7}{|c|}{ NO FRONT PRESSURE } \\
\hline $3^{*}$ & Garbonic Acid & 3.7 & 62.87 & 44.73 & 6.82 & 14.81 \\
\hline $4^{*}$ & Carbonic Acid & 3.4 & 72.59 & 46.72 & 7.26 & 14.82 \\
\hline \multicolumn{7}{|c|}{ HIGH PRESSURE ( 350 psi front pressure, 450 psi back pressure) } \\
\hline & YELLOW POPLAR & & 100.00 & 46.72 & 15.78 & 22.90 \\
\hline \multicolumn{7}{|c|}{ PERCOLATION REACTIONS using Carbonic Acid } \\
\hline 5 & $150-19015 \mathrm{~min}$ & 3.4 & 65.70 & 50.89 & 2.80 & 8.39 \\
\hline 6 & increase time to 20 & 3.4 & 60.35 & 44.91 & 2.08 & 12.78 \\
\hline 7 & 15 min, slow flow & 3.4 & 77.13 & 43.91 & 6.80 & 20.94 \\
\hline & HYBRID POPLAR & & 100.00 & 44.65 & 13.88 & 26.07 \\
\hline \multicolumn{7}{|c|}{ BATCH REACTIONS using Carbonic Acid } \\
\hline 8 & batch $20 \mathrm{~min}, 150$ & 3.4 & 93.00 & 46.86 & 11.71 & 12.60 \\
\hline 9 & batch $45 \mathrm{~min}, 150$ & 3.4 & 92.54 & 42.58 & 11.28 & 25.33 \\
\hline
\end{tabular}

Note: all sugars and lignin content in the table based on oven-dry untreated biomass.

XMG: the total Xylan, Mannan, and Galactan

*Pretreatment conditions: $180 \mathrm{C}, 20 \mathrm{~min}$, flow rate $4 \mathrm{~mL} / \mathrm{min}, 350$ psi backpressure 
to eliminate any dissociation prior to the percolation unit, and to minimize the carbonic acid dissociation within the percolation unit. Runs 5, 6, and 7 show the results under randomly chosen reaction conditions. The time and temperature intervals were centered around the known optimal conditions for sulfuric acid pretreatment with variations above and below. Trial 6 , run at the optimal temperature with a slightly lengthened reaction time, proved to be the most promising. Data in the run was comparable to single stage sulfuric acid pretreatment.

In Runs 8 and 9, highly pressurized batch reactions were carried out. Neither reaction proved to be successful in removing XMG or lignin. Further investigation may provide better results. However, due to the low stability (high dissociation) of carbonic acid, it seems that pressurized batch reactions will prove to be an effective treatment method.

\section{Optimization of Pressurized Carbonic Acid Pretreatment}

Our confirmation efforts resumed isolating the conditions of run 6; under 350 psi front pressure, 450 psi back pressure, reaction time 20 minutes per stage at $150 \mathrm{C}$ and $190 \mathrm{C}$, with a flow rate of $4.0 \mathrm{~mL} / \mathrm{min}$. Since the reaction time was slightly longer than the optimal for sulfuric acid, the sulfuric acid concentration used for comparison was decreased to $0.025 \mathrm{wt} \%$. This adjustment kept the degradation of sugars due to prolonged exposure to a more concentrated strong acid to a minimum. Table 7 shows four of our confirmation runs. The data reflects that overall the carbonic acid was comparable to sulfuric acid. Under carbonic acid treatment, 5-6\% more of the original glucan was retained. The effect on lignin was the same for both solvents, (slightly over half was removed). For hemicellulose carbonic acid was not quite as efficient at removal, leaving $2-3 \%$ of the original in the sample. The recovery of the hemicellulose in the liquid stream was much higher for carbonic acid (almost 100\%) than for sulfuric acid (around $87 \%$ ). The percent solid remaining was significantly higher, $9 \%$, for carbonic acid than for sulfuric acid under the same conditions. 


\section{Table 7. The Effect of Solvent Type on the Distribution of Sugars Between Solid Residue and Liquid Hydrolyzate}

Pretreatment Conditions: $150 \mathrm{C} / 20 \mathrm{~min}-190 \mathrm{C} / 20 \mathrm{~min}$, flow rate $4.0 \mathrm{~mL} / \mathrm{min}, 350$ psi back pressure.

\begin{tabular}{|c|c|c|c|c|c|c|c|c|c|c|}
\hline \multirow{2}{*}{$\begin{array}{l}\text { Confirmation } \\
\text { Run Number }\end{array}$} & \multicolumn{2}{|c|}{$\mathrm{pH}$} & \multirow{2}{*}{$\begin{array}{l}\% \text { solid } \\
\text { remaining } \\
\end{array}$} & \multicolumn{3}{|c|}{$\%$ Glucan } & \multicolumn{3}{|c|}{$\%$ Hemicellulose } & \multirow{2}{*}{$\begin{array}{c}\% \text { Klasor } \\
\text { Lignin } \\
\end{array}$} \\
\hline & initial & final & & Solid & Liquid & Total & Solid & Liquid & Total & \\
\hline untreated & -.-- & ---- & 100.00 & 46.72 & --------- & 46.72 & 18.02 & ---------ינ- & 18.02 & 22.90 \\
\hline Water & 4 & 3.1 & 59.30 & 43.66 & 1.43 & 45.09 & 1.60 & 16.61 & 18.21 & 11.54 \\
\hline Water & 4 & 3.1 & 61.09 & $41.99^{\circ}$ & 1.50 & 43.49 & 1.50 & 17.23 & 18.73 & 12.04 \\
\hline Carbonic Acid & 3.4 & 3.3 & 61.10 & 47.51 & 1.52 & 49.03 & 2.93 & 15.16 & 18.09 & 11.07 \\
\hline Carbonic Acid & 3.4 & 3.3 & 61.71 & 47.56 & 1.33 & 48.89 & 2.44 & 15.03 & 17.47 & 11.26 \\
\hline Sulfuric Acid & 2.5 & 2.4 & 53.50 & 41.54 & 4.42 & 45.96 & 0.00 & 16.35 & 16.35 & 11.68 \\
\hline Sulfuric Acid & 2.5 & 2.4 & 52.56 & 41.01 & 5.23 & 46.24 & 0.00 & 16.63 & 16.63 & 11.39 \\
\hline
\end{tabular}

Note: all sugars and lignin content based on the original oven-dry untreated biomass

* Carbonic acid formed under 350 psi, pH 3.4

** Sulfuric acid concentration $0.025 \mathrm{wt} \%, \mathrm{pH} 2.5$

${ }^{* * *}$ Carbonic acid runs were conducted with 350 psi front pressure and 450 psi back pressure 
The distribution of hemicellulose sugars and other components is shown in Table 8. The only significant difference between carbonic acid treatment and sulfuric acid treatment hydrolyzates is in the amount of hemicellulose in the monomer form. For sulfuric acid nearly half of the hemicellulose was present in the monomer form. In the carbonic acid hydrolyzate, only about $13 \%$ of the hemicellulose was present in the monomer form.

\section{Enzymatic Digestibility}

Figure 13 shows the enzymatic digestibility of the yellow poplar after the various pretreatments. The sulfuric acid pretreated sample reached its maximum digestibility of $90 \%$ after 36 hours and remained constant there. The carbonic acid pretreated sample was digested much more slowly. It reached its peak of $81 \%$ after 72 hours. This $9 \%$ difference in digestibility appears to be significant, and warrants more investigation. It is also worth considering that the $81 \%$ digestibility of carbonic acid treated may yield a higher amount of glucose per gram of untreated biomass than the $90 \%$ digestibility of the sulfuric acid. This is due to the fact that the carbonic acid treated samples retained $47 \%$ of the original biomass as glucan compared to the $41 \%$ retained by the sulfuric acid treated samples. On the basis of grams glucan yielded per gram untreated biomass, both treatments are about equal with only a slight edge going to the carbonic acid treated sample ( 0.389 grams glucan/gram untreated biomass for the carbonic acid treated sample, 0.369 grams glucan/gram untreated biomass for the sulfuric acid treated sample).

\section{Hemicellulose Removal/Parameter Optimization}

Some concern was raised that the hemicellulose fraction left in the solid was higher than that from dilute sulfuric acid pretreatment (2-3\%). Our next work was focused on removing residual hemicellulose by further optimization of three operational parameters: second stage (high temperature) reaction temperature, first stage (low temperature) reaction temperature, and 


\section{Table 8. Effect of Solvent Type Distribution of Hemicellulose Sugars and Other Components in Primary Hydrolyzate.}

Pretreatment Conditions: $150 \mathrm{C} / 20 \mathrm{~min}-190 \mathrm{C} / 20 \mathrm{~min}$, flow rate $4.0 \mathrm{~mL} / \mathrm{min}, 350 \mathrm{psi}$ back pressure.

\begin{tabular}{|c|c|c|c|c|c|c|c|}
\hline \multirow{2}{*}{$\begin{array}{l}\text { Solvent } \\
\text { Used }\end{array}$} & \multicolumn{2}{|c|}{ Hemicellulose } & \multirow{2}{*}{$\begin{array}{c}\text { Formic Acid } \\
(\mathrm{g} / \mathrm{L})\end{array}$} & \multirow{2}{*}{$\begin{array}{c}\text { Acetic Acid } \\
(\mathrm{g} / \mathrm{L})\end{array}$} & \multirow{2}{*}{$\begin{array}{l}\text { HMF } \\
(\mathrm{g} / \mathrm{L})\end{array}$} & \multirow{2}{*}{$\begin{array}{c}\text { Furfural } \\
(\mathrm{g} / \mathrm{L})\end{array}$} & \multirow[t]{2}{*}{$\mathrm{pH}$} \\
\hline & $\%$ monomer & $\%$ oligomer & & & & & \\
\hline Water & 3.19 & 13.42 & 0.013 & 0.97 & 0.00 & 0.08 & 3.1 \\
\hline Water & 3.46 & 13.75 & 0.015 & 1.07 & 0.00 & 0.06 & 3.1 \\
\hline Carbonic Acid & 1.88 & 13.83 & 0.000 & 0.83 & 0.01 & 0.18 & 3.3 \\
\hline Carbonic Acid & 2.50 & 12.99 & 0.000 & 0.75 & 0.00 & 0.00 & 3.3 \\
\hline Sulfuric Acid & 6.88 & 9.92 & 0.000 & 1.20 & 0.00 & 0.00 & 2.4 \\
\hline Sulfuric Acid & 7.59 & 9.59 & 0.000 & 1.13 & 0.00 & 0.09 & 2.4 \\
\hline
\end{tabular}

Note: all sugars and lignin content based on the original oven-dry untreated biomass

* Carbonic acid formed under 350 psi, pH 3.4

** Sulfuric acid concentration 0.025 wt \%, pH 2.5

${ }^{* * \star}$ Crabonic acid runs were conducted with 350 psi front pressure and 450 psi back pressure

XMG: the total Xylan, Mannan, and Galactan 


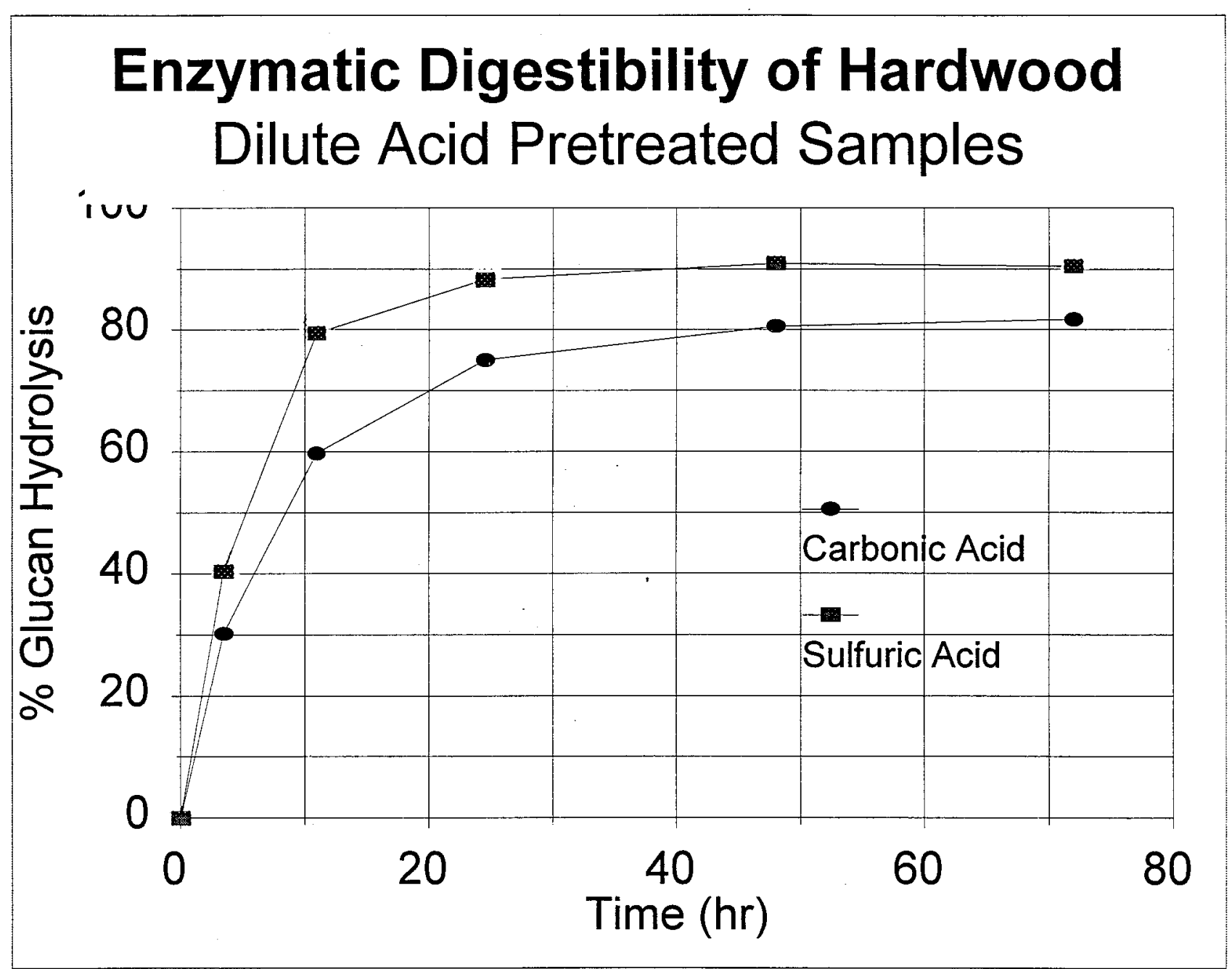

Figure 13. Enzymatic Digestibility of yellow poplar hardwood 
reaction time per stage. The base pretreatment conditions were $150^{\circ} \mathrm{C} / 20$ minutes $-190^{\circ} \mathrm{C} /$ 20 minutes, $4.0 \mathrm{~mL} / \mathrm{min}$ flow rate, 350 psi front pressure, and 450 psi back pressure. The feed carbonic acid was prepared by saturation of DI water with pure $\mathrm{CO}_{2}$ at 350 psi, room temperature.

\section{Variation of Second Stage Reaction Temperature}

For this series of experiments, the first stage temperature was maintained at $150{ }^{\circ} \mathrm{C}$ while the second stage temperature varied from $180^{\circ} \mathrm{C}$ to $200^{\circ} \mathrm{C}$. Table 9 shows the distribution of sugars and other components at various second stage temperatures. The results show little change between the $180^{\circ} \mathrm{C}$ and $190^{\circ} \mathrm{C}$ runs. However a notable decrease in the percent hemicellulose retained in the solid is seen between the $190^{\circ} \mathrm{C}$ and $200^{\circ} \mathrm{C}$ runs, $(2.41 \%, 0.79 \%)$. Unfortunately this decrease in hemicellulose is accompanied by a decrease in the overall hemicellulose balance. The nearly $3 \%$ missing from the hemicellulose balance may be due to decomposition. The overall glucan balance is also slightly less at $200^{\circ} \mathrm{C}$ than at $190{ }^{\circ} \mathrm{C}$. This again indicates some possible sugar decomposition.

The results also revealed a notable point in the delignification effects of the pretreatment. In the higher temperature pretreatment runs $\left(200^{\circ} \mathrm{C}\right)$, unusually high delignification was observed. To this point, we have not fully explored the delignification aspect in carbonic acid pretreatment. The early data in these experiments indicate that at least $60 \%$ and even as much as $80 \%$ of the lignin can be removed by treatment with carbonic acid. It is much higher than those observed under pure water or sulfuric acid treatment. It is speculated that introduction of carbonic acid creates reaction conditions less acidic than those of pure water because of the buffering action of carbonates. It is also to be noted that carbonic acid is less acidic than acetic acid which is a product of pure water treatment. 
Table 9. The Effect of Second Stage (High Temperature Stage) Temperature Change on the Distribution Between Solid Residue and Liquid Hydrolyzate

Pretreatment Conditions: $150 \mathrm{C} / 20 \mathrm{~min}$ - Variable $\mathrm{C} / 20 \mathrm{~min}$, solvent carbonic acid ${ }^{*}$, flow rate $4.0 \mathrm{~mL} / \mathrm{min}, 350$ psi front pressure, 450 psi back pressure

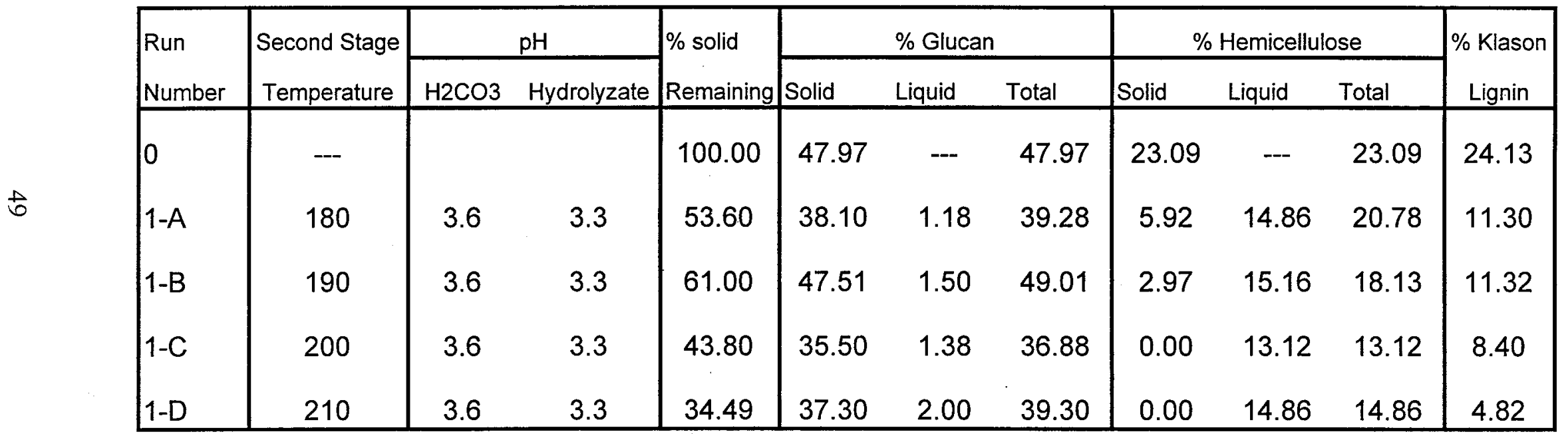

Note: all sugars and lignin content based on the original oven-dry untreated biomass

* Carbonic acid was formed under 350 psi 
Table 10 indicates the distribution of liquid components in the primary hydrolyzate. The most notable trend is a shift of hemicellulose sugars from the oligomer to monomer form as the temperature increases.

In summary, the increase in the second stage temperature promotes higher degree of hemicellulose removal as well as delignification. However, decomposition of sugars becomes noticeable at or above $200^{\circ} \mathrm{C}$.

\section{First Stage Reaction Temperature}

In an attempt to determine whether the hemicellulose remaining in the solid is the easily hydrolyzed or more difficultly hydrolyzed portion, we explored the effect of change of low temperature (first stage). With the second stage temperature fixed at $190^{\circ} \mathrm{C}$, we varied the first stage temperature from $140{ }^{\circ} \mathrm{C}$ to $170^{\circ} \mathrm{C}$. The results, shown in Table 11 , indicate that a first stage temperature change has little or no effect on hemicellulose retained in solid, overall hemicellulose balance, glucan dissolved in hydrolyzate, and overall glucan balance. It is therefore concluded that the easily hydrolyzed portion of the hemicellulose is completely hydrolyzed under reaction conditions with a low temperature at or below $140{ }^{\circ} \mathrm{C}$. Also, since the hemicellulose in question was still retained despite the change in the first stage temperature, then that hemicellulose must be of the more difficultly hydrolyzed type. The insignificant difference in the sugar balances indicates that little to no decomposition takes place at temperatures below $170{ }^{\circ} \mathrm{C}$. From the standpoint of the energy input, we conclude that the optimal first stage temperature is between $140^{\circ} \mathrm{C}$ and $150^{\circ} \mathrm{C}$.

Table 12 shows the distribution of components in the primary hydrolyzate. This data also shows little variation with first stage temperature change. It indicates that a higher first stage temperature helps to convert oligomers to monomers.

In summary, there is little to no effect of changing the first stage reaction temperature. 
Table 10. Effect of Second Stage Temperature Increase on the Distribution of Hemicellulose Sugars and Other Compoenents in Primary Hydrolyzate

Pretreatment Conditions: $150 \mathrm{C} / 20 \mathrm{~min}$ - Variable $\mathrm{C} / 20 \mathrm{~min}$, solvent carbonic acid ${ }^{\star}$, flow rate $4.0 \mathrm{~mL} / \mathrm{min}$, 350 psi front pressure, 450 psi back pressure

\begin{tabular}{|c|c|c|c|c|c|c|c|}
\hline \multirow{2}{*}{$\begin{array}{l}\text { Run } \\
\text { Number }\end{array}$} & \multirow{2}{*}{$\begin{array}{c}\text { Second Stage } \\
\text { Temperature }\end{array}$} & \multicolumn{2}{|c|}{ Hemicellulose } & \multirow{2}{*}{$\begin{array}{c}\text { Acetic Acid } \\
(\mathrm{g} / \mathrm{L})\end{array}$} & \multirow{2}{*}{$\begin{array}{l}\text { HMF } \\
(\mathrm{g} / \mathrm{L}) \\
\end{array}$} & \multirow{2}{*}{$\begin{array}{l}\text { Furfural } \\
(g / L)\end{array}$} & \multirow[t]{2}{*}{$\mathrm{pH}$} \\
\hline & & $\%$ monomer & $\%$ oligomer & & & & \\
\hline $1-A$ & 180 & 1.51 & 13.35 & 0.661 & 0 & 0.0203 & 3.3 \\
\hline $1-B$ & 190 & & & & & & \\
\hline $1-C$ & 200 & 2.09 & 11.03 & 0.651 & 0 & 0.0203 & 3.3 \\
\hline 1-D & 210 & 4.43 & 10.43 & 0.759 & 0 & 0.0283 & 3.3 \\
\hline
\end{tabular}

Note: all sugars and lignin content based on the original oven-dry untreated biomass

* Carbonic acid was formed under 350 psi 
Table 11. The Effect of First Stage (Low Temperature Stage) Temperature Change on the Distribution Between Solid Residue and Liquid Hydrolyzate

Pretreatment Conditions: Variable / $20 \mathrm{~min}-190 \mathrm{C} / 20 \mathrm{~min}$, solvent carbonic acid*, flow rate $4.0 \mathrm{~mL} / \mathrm{min}, 350$ psi front pressure, 450 psi back pressure

\begin{tabular}{|c|c|c|c|c|c|c|c|c|c|c|c|}
\hline \multirow{2}{*}{\begin{tabular}{|l} 
Run \\
Number \\
\end{tabular}} & \multirow{2}{*}{\begin{tabular}{|c|} 
First Stage \\
Temperature \\
\end{tabular}} & \multicolumn{2}{|r|}{$\mathrm{pH}$} & \multirow{2}{*}{$\begin{array}{l}\% \text { solid } \\
\text { Remaining }\end{array}$} & \multicolumn{3}{|c|}{$\%$ Glucan } & \multicolumn{3}{|c|}{$\%$ Hemicellulose } & \multirow{2}{*}{$\begin{array}{c}\% \text { Klasor } \\
\text { Lignin } \\
\end{array}$} \\
\hline & & $\mathrm{H} 2 \mathrm{CO} 3$ & Hydrolyzate & & Solid & Liquid & Total & Solid & Liquid & Total & \\
\hline 0 & -- & & & 100.00 & 47.97 & - & 47.97 & 23.09 & -- & 23.09 & 24.13 \\
\hline $2-A$ & 140 & 3.6 & 3.3 & & & 1.38 & 1.38 & & 16.44 & 16.44 & \\
\hline $2-B$ & 150 & 3.6 & 3.3 & & & & 0.00 & & & 0.00 & \\
\hline $2-C$ & 160 & 3.6 & 3.3 & & & 1.20 & 1.20 & & 14.65 & 14.65 & \\
\hline 2-D & 170 & 3.6 & 3.3 & & & 1.42 & 1.42 & & 16.95 & 16.95 & \\
\hline
\end{tabular}

Note: all sugars and lignin content based on the original oven-dry untreated biomass

* Carbonic acid was formed under 350 psi 
Table 12. Effect of First Stage Temperature Change on the Distribution of Hemicellulose Sugars and Other Compoenents in Primary Hydrolyzate

Pretreatment Conditions: variable $\mathrm{C} / 20 \mathrm{~min}-190 \mathrm{C} / 20 \mathrm{~min}$, solvent carbonic acid ${ }^{\star}$, flow rate $4.0 \mathrm{~mL} / \mathrm{min}$, 350 psi front pressure, 450 psi back pressure

\begin{tabular}{|c|c|c|c|c|c|}
\hline \multicolumn{2}{|c|}{ Hemicellulose } & \multirow{2}{*}{$\begin{array}{c}\text { Acetic Acid } \\
(\mathrm{g} / \mathrm{L})\end{array}$} & \multirow{2}{*}{$\begin{array}{l}\text { HMF } \\
\text { (g/L) }\end{array}$} & \multirow{2}{*}{$\begin{array}{c}\text { Furfural } \\
(\mathrm{g} / \mathrm{L})\end{array}$} & \multirow[t]{2}{*}{$\mathrm{pH}$} \\
\hline$\%$ monomer & $\%$ oligomer & & & & \\
\hline 2.67 & 13.77 & 0.77 & & 0.027 & 3.3 \\
\hline 1.11 & 13.54 & 0.662 & & 0.016 & 3.3 \\
\hline 1.16 & 15.79 & 0.77 & & 0.027 & 3.3 \\
\hline
\end{tabular}

Note: all sugars and lignin content based on the original oven-dry untreated biomass

* Carbonic acid was formed under 350 psi 


\section{Reaction Time Per Stage}

For the study on reaction time, we chose the base treatment conditions of $150{ }^{\circ} \mathrm{C}$ first stage and $190^{\circ} \mathrm{C}$ second stage. The reaction time per stage varied from 15 to 30 minutes. Table 13 shows the distribution of sugars and other components for various reaction times. The distribution of sugars and the overall balances are almost identical to those of first stage temperature change experiments (seen in Table 12). Hemicellulose retained, glucan dissolved, and overall sugar balances change only slightly as the reaction time was changed from 15 to 30 minutes per stage. As stated previously it appears that the sugars are not decomposed when they are exposed to temperatures at or below $170^{\circ} \mathrm{C}$. The amount of decomposition is a function both of temperature and exposure time. Since it is observed that the total recovery for the sugars is approximately constant as the exposure time increases in these runs, then it can be concluded that relatively little decomposition takes place at these selected temperatures. In the case of 190 ${ }^{\circ} \mathrm{C}$ second stage treatment, the overall sugar balance does not vary with reaction time indicating that there is little decomposition. We thus conclude that carbonic acid treatment at $190{ }^{\circ} \mathrm{C}$ is insufficient to completely hydrolyze the hemicellulose portion, even with increased reaction times (30 minutes).

The component distribution in the liquid, shown in Table 14, shows a slight increase in the amount of hemicellulose present in the monomer form. This indicates that $190{ }^{\circ} \mathrm{C}$ is adequate cleavage of the oligomer if given sufficient reaction time.

In summary, $190^{\circ} \mathrm{C}$ is a high enough temperature to hydrolyze the oligomers into monomers, but is insufficient to fully hydrolyze the more difficultly hydrolyzed fraction of the two hemicelluloses. Extended exposure to $190{ }^{\circ} \mathrm{C}$ has little effect on the overall sugar balances and therefore causes little decomposition. We therefore project that a temperature between $190^{\circ} \mathrm{C}$ and $200^{\circ} \mathrm{C}$ (Table 9) may allow complete hydrolysis of the difficultly hydrolyzed portion of the hemicellulose. 
Table 13. The Effect of Reaction Stage Length Change on the Distribution Between Solid Residue and Liquid Hydrolyzate

Pretreatment Conditions: $150 \mathrm{C}-190 \mathrm{C}$, solvent carbonic acid*, flow rate $4.0 \mathrm{~mL} / \mathrm{min}, 350$ psi front pressure, 450 psi back pressure

\begin{tabular}{|c|c|c|c|c|c|c|c|c|c|c|c|}
\hline \multirow{2}{*}{\begin{tabular}{|l} 
Run \\
Number \\
\end{tabular}} & \multirow{2}{*}{\begin{tabular}{|c} 
Reaction Time \\
$\mathrm{min} /$ stage
\end{tabular}} & \multicolumn{2}{|r|}{$\mathrm{pH}$} & \multirow{2}{*}{$\begin{array}{l}\% \text { solid } \\
\text { Remaining }\end{array}$} & \multicolumn{3}{|c|}{ \% Glucan } & \multicolumn{3}{|c|}{$\%$ Hemicellulose } & \multirow{2}{*}{$\begin{array}{c}\% \text { Klason } \\
\text { Lignin } \\
\end{array}$} \\
\hline & & $\mathrm{H} 2 \mathrm{CO} 3$ & Hydrolyzate & & Solid & Liquid & Total & Solid & Liquid & Total & \\
\hline 0 & --- & & & 100.00 & 47.97 & -- & 47.97 & 23.09 & --- & 23.09 & 24.13 \\
\hline $3-A$ & 15 & 3.6 & 3.3 & & & 1.58 & 1.58 & & 19.76 & 19.76 & \\
\hline $3-B$ & 20 & 3.6 & 3.3 & & & & 0.00 & & & 0.00 & \\
\hline $3-C$ & 25 & 3.6 & 3.3 & & & 1.01 & 1.01 & & 12.54 & 12.54 & \\
\hline 3-D & 30 & 3.6 & 3.3 & & & 1.03 & 1.03 & & 11.70 & 11.70 & \\
\hline
\end{tabular}

Note: all sugars and lignin content based on the original oven-dry untreated biomass

* Carbonic acid was formed under 350 psi 
Table 14. Effect of Change in Reaction Stage Length on the Distribution of Hemicellulose Sugars and Other Components in Primary Hydrolyzate

Pretreatment Conditions: $150 \mathrm{C}-190 \mathrm{C}$, Solvent carbonic acid ${ }^{\star}$, flow rate $4.0 \mathrm{~mL} / \mathrm{min}$, $350 \mathrm{psi}$ front pressure, $450 \mathrm{psi}$ back pressure

\begin{tabular}{|c|c|c|c|c|c|c|c|}
\hline \multirow{2}{*}{$\begin{array}{l}\text { Run } \\
\text { Number }\end{array}$} & \multirow{2}{*}{$\begin{array}{c}\text { Reaction Time } \\
\text { Min / Stage }\end{array}$} & \multicolumn{2}{|c|}{ Hemicellulose } & \multirow{2}{*}{$\begin{array}{l}\text { Acetic Acid } \\
(\mathrm{g} / \mathrm{L}) \\
\end{array}$} & \multirow{2}{*}{$\begin{array}{l}\text { HMF } \\
(\mathrm{g} / \mathrm{L})\end{array}$} & \multirow{2}{*}{$\begin{array}{c}\text { Furfural } \\
(\mathrm{g} / \mathrm{L})\end{array}$} & \multirow[t]{2}{*}{$\mathrm{pH}$} \\
\hline & & $\%$ monomer & $\%$ oligomer & & & & \\
\hline $3-A$ & 15 & 2.35 & 17.41 & 0.868 & 0 & 0.027 & 3.3 \\
\hline $3-B$ & 20 & & & & & & \\
\hline $3-C$ & 25 & 1.81 & 10.73 & 0.542 & 0 & 0.014 & 3.3 \\
\hline 3-D & 30 & 2.32 & 9.38 & 0.542 & 0 & 0.014 & 3.3 \\
\hline
\end{tabular}

Note: all sugars and lignin content based on the original oven-dry untreated biomass

* Carbonic acid was formed under 350 psi 


\section{Delignification}

As previously stated, the study in this segment has raised our interest in using carbonic acid as a potential delignification agent as we have observed $60 \%$ to $80 \%$ delignification in a number of carbonic acid experiments. The most notable case is shown on Table 13. In the case where both stage temperatures were set, and only reaction times were changed, there was high degree of dilignification. During this treatment there was no noticable difference in sugar distribution or overall balance. This indicates that operations near $190^{\circ} \mathrm{C}$ may find its way to a method that facilitates delignification without decomposing the desired sugars.

\section{Future Study}

If the opportunity is presented for future work. We plan to investigate the temperature range from $190^{\circ} \mathrm{C}$ to $200^{\circ} \mathrm{C}$ over extended reaction times, in terms of hemicellulose retained in the solid and for sugar decomposition. We plan to experiment with on-line hydrolyzate sampling during the stages to determine under which conditions the hemicellulose is dissolved. We also propose to apply a progressive change in second stage temperature, that is to allowing the reactor to continually increase from the first stage temperature. We intend to verify if this improves the process in maximizing hemicellulose solulilization and minimizing overall sugar decomposition.

With regard to lignin experimentation, we plan to reconfirm our delignification results and examine the temperature effect more closely. 
Task 3. NREL Sample Analysis

The following biomass solid and liquid samples were analyzed and reported directly to the NREL project coordinator, Mr. Robert Torget:

Solid Analysis (analyzed for sugar content, Klason Lignin, acid soluble lignin, and ash)

HW $220 \mathrm{~A}$

HW 240 A

INHPOP 42

2264-55 A

2264-56 A

2264-57 A

2264-58 A

2264-59 A

2264-60 A

2264-61 A

2264-62 A

2264-63 A

2264-70 A

2264-71 A

2264-72 A

2264-73 A

2264-74 A

2264-77 A

2264-78 A

2264-79 A

Douglas fir (reported to Nick Nagle)

INHFIR 170

INHFIR 190

INHFIR 210

INHFIR 220

Reactor series (reported to Nick Nagle)

Reactor 1

Reactor 2

Reactor 3

Reactor 4

Reactor 5

Corn stover solids

Water - 95

Water - 120 


$$
\begin{aligned}
& \text { Water- } 140 \\
& \text { Water- } 160 \\
& \text { Acid - } 140 \\
& \text { Acid - } 160 \\
& \text { Acid - } 180 \\
& \text { Acid - } 210 \\
& \text { Acid - } 195 / 225
\end{aligned}
$$

Total solid samples: 38

Liquid Analysis (analyzed for sugars, acetic acid, furfural, formic acid, and HMF)

HW 200 A

HW $200 \mathrm{~B}$

HW $220 \mathrm{~A}$

HW 220 A washate

HW 240 A

INHPOP 42

2264-53 A Effluent 1

2264-53 A Effluent 2

2264-54 A Effluent 1

2264-54 A Effluent 2

2264-55 A Effluent 1

2264-55 A Effluent 2

2264-56 A Effluent 1

2264-56 A Effluent 2

2264-57 A Effluent 1

2264-57 A Effluent 2

2264-58 A Effluent 1

2264-58 A Effluent 2

2264-59 A Effluent 1

2264-59 A Effluent 2

2264-60 A Effluent 1

2264-60 A Effluent 2

2264-61 A Effluent 1

2264-61 A Effluent 2

2264-62 A Effluent 1

2264-62 A Effluent 2

2264-63 A Effluent 1

2264-63 A Effluent 2

2264-70 A Effluent 1

2264-70 A Effluent 2

2264-71 A Effluent 1

2264-71 A Effluent 2

2264-72 A Effluent 1

2264-72 A Effluent 2 
2264-73 A Effluent 1

2264-73 A Effluent 2

2264-74 A Effluent 1

2264-74 A Effluent 2

2264-77 A Effluent 1

2264-77 A Effluent 2

2264-78 A Effluent 1

2264-78 A Effluent 2

2264-79 A Effluent 1

2264-79 A Effluent 2

Douglas fir

INHFIR 170, 5 minutes

INHFIR 170, 30 minutes

INHFIR 190, 30 minutes

INHFIR 210, 5 minutes

INHFIR 210, 30 minutes

INHFIR 220, 5 minutes

INHFIR 220, 10 minutes

INHFIR 220, 15 minutes

INHFIR 220, 20 minutes

INHFIR 220, 30 minutes

Reactor series

Reactor 1

Reactor 2

Reactor 3

Reactor 4

Corn stover liquids

Water - 95/20

Water - 95/40

Water - 95/60

Water - 120/10

Water - 120/20

Water - 120/30

Water - 120/leakage

Water - 140/10

Water - 140/20

Water - 140/30

Water - 140/leakage

Acid - 140/10

Acid - 140/20

Acid - 140/30

Water - 160/10 


$$
\begin{aligned}
& \text { Water - 160/20 } \\
& \text { Water - 160/30 } \\
& \text { Water - 160/leakage } \\
& \text { Acid - 160/10 } \\
& \text { Acid - 160/20 } \\
& \text { Acid - 160/30 } \\
& \text { Acid - 160/leakage } \\
& \text { Acid - 180/10 } \\
& \text { Acid - 180/20 } \\
& \text { Acid - 180/30 } \\
& \text { Acid - 195/30 } \\
& \text { Acid - 210/10 } \\
& \text { Acid - 210/20 } \\
& \text { Acid }-210 / 30 \\
& \text { Acid - 225/30 }
\end{aligned}
$$

Total liquid samples: 100 
Appendix 1.

Fortran Source Codes for

Modeling and Simulation of Shrinking Bed Percolation Reactor Operation 
PROGRAM rshrink

ccccccccccccccccccccccccccccccccccccccccccccccccccccccccccccccccccccccccccccccc

c This program calculates the optimum yield of xylose_oligomer + xylose,

c conversion, and shrinking factor, based on the previous obtained

c optimun conditions for two-stage reverse-flow mode.

$\mathrm{c}$

c BIOMASS: Corn Cobs/Corn Stover Mixture (CCSM)

$\mathrm{c}$

c OPERATION: two-stage reverse flow, shrinking bed operation

$\mathrm{c}$

c The reaction pattern:

c $\quad H f(x y l a n) \backslash 1 \quad$ soluble $3 \quad 4$ decomposed

c

c

$\mathrm{c}$

c INPUT: temperature (tem $(1,2)$ ), acid concentration (A), tau1 and tau2

c reaction order w.r.t. $\operatorname{acid}(\mathrm{n}(\mathrm{i}))$

c fraction of fast hemicellulose (F1),

c activation energy (E(i)) with frequency factor ( $\mathrm{k} 0(\mathrm{i}))$,

c total_xylan_as_xylose/total_liquid_volume $(\mathrm{H} 0)$, and xylan percentage

$\mathrm{c}$

c OUTPUT: yield, conversion, shrinking factor, tau.

$\mathrm{c}$

$\mathrm{c}$

$\mathrm{c}$

$\mathrm{c}$

c This program involes:

c 1. hydrolysis for a differential tau, whish is regraded as a

$\mathrm{c}$

c

$\mathrm{c}$

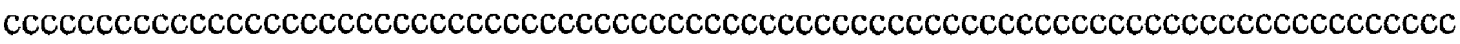

$\mathrm{c}$

$\mathrm{c}$

$\mathrm{c}$

real

peuso-nonshrinking mode,

2. compression after each reaction of differential tau, w/o reaction. specification for local variables

real

real

alpha(4), beta(4), gamma(4), $\operatorname{tau}(4), \operatorname{tem}(2), F 1$, a, xi_c

real

theta, eta, xi, theta 0 , eta 0 , xi0, gara, tauc, taut

real

real

L, L0, L1, Lo, H0, Hfo, Hs0, yo(4), yx(4), y(4), yl, y2 $\mathrm{y} 3, \mathrm{y} 4$

real

$y 1 t, y 2 t, y 3 t, y 4 t, y_{-} 1 a t, y_{-} 1 b t, y \_2 t, y t o t$, tau1, tau2

yo_1b, yx1_1b, yx2_1b, ty, Cp, u, taulset

yo 2 , yx2, yo2t, yx2t, xc(800), Ht(800), y_1btc 
c

c

a

tem(1)

tem(2)

n

$\mathrm{m}$

c

beta(1)

beta(2)

beta(3)

beta(4)

c

c

c

$\operatorname{tau}(1)$

$\operatorname{tau}(2)$

$\operatorname{tau}(3)$

$\operatorname{tau}(4)$

c

c

c

F1

Ho

Ho

$\mathrm{HfO}$

$\mathrm{Hs} 0$

Lo

LO

c

$\mathrm{u}$

taulset

c

c

c

theta 0

eta 0

xi0

gara

c

c

c

c

$* * * * * *$

c input operational data: $a=$ acid conc. $\%$. tem=tempearture

$$
\begin{aligned}
& =0.074 \\
& =180 . \\
& =190 . \\
& =800 \\
& =800
\end{aligned}
$$

$=2.662$

$=0.289$

$=14.554$

$=2.838$

input differential tau

$$
\begin{aligned}
& =0.005 \\
& =\operatorname{tau}(1) \\
& =0.005 \\
& =\operatorname{tau}(3)
\end{aligned}
$$

operation parameters ( $\mathrm{L} 0-\mathrm{cm}, \mathrm{u}-\mathrm{cm} / \mathrm{min}$ )

$$
\begin{aligned}
& =0.99 \\
& =3.333 \\
& =\mathrm{H} 0 \\
& =\mathrm{fl}{ }^{*} \mathrm{Ho} \\
& =(1-\mathrm{fl})^{*} \mathrm{Ho} \\
& =15.24 \\
& =\mathrm{Lo}
\end{aligned}
$$

$$
=2 \text {. }
$$$$
=0.4
$$

input initial shrinking parameters

$$
\begin{aligned}
& =0 . \\
& =0.2 \\
& =1 . \\
& =0.315
\end{aligned}
$$

calculate alpha beta, gammma and yield

FOR REACTOR la calculate conversion and other shrinking parameters 


$$
\text { c }
$$

$\mathrm{c}$

xi_c $\quad=1$

taut $\quad=0$.

y_1at $\quad=0$.

y_lbt $\quad=0$.

y_2t $\quad=0$.

y1t $\quad=0$.

$\mathrm{y} 2 \mathrm{t}=0$

y3t $\quad=0$

$\mathrm{y} 4 \mathrm{t} \quad=0$

ytot $\quad=0$.

$\mathrm{c}$

do $101 \mathrm{i}=1, \mathrm{n}$

c

call al_ga (alpha(1), alpha(2), beta(1), beta(2), gamma(1),

$+\operatorname{gamma}(2), \operatorname{tem}(1), \mathrm{a}, \mathrm{u}, \mathrm{L} 0)$

c $\operatorname{print}^{*}, \operatorname{beta}(1), \operatorname{beta}(2), \operatorname{beta}(1) / \operatorname{beta}(2)$

c

$$
\begin{aligned}
& \text { do } 555 \mathrm{k}=1,2 \\
& \text { call yld_1a_2 (yo(k), yx(k), alpha(k), beta(k), }
\end{aligned}
$$$$
+
$$$$
\mathrm{y}(\mathrm{k}) \quad=\mathrm{yo}(\mathrm{k})+\mathrm{yx}(\mathrm{k})
$$

c print*, L0, yo(1)/yx(1), yo(2)/yx(2)

\section{$555 \quad$ continue}

.

call hemi (theta, eta, xi, HCf, HCs, tau(1),

$$
\begin{aligned}
& +\quad \operatorname{beta}(1), \operatorname{beta}(2), \text { theta } 0 \text {, eta0, gara, } \mathrm{HfO}, \mathrm{Hs} 0) \\
& \text { c convert tau in terms of initial tau loading -:) } \\
& \mathrm{xc}(\mathrm{i}) \quad=\mathrm{xi} 0 \\
& \mathrm{Ht}(\mathrm{i}) \quad=\mathrm{HfO}+\mathrm{Hs} 0 \\
& \text { xi_c } \quad=x i_{-} c * x i 0 \\
& \text { tauc } \quad=\operatorname{tau}(1)^{*} \mathrm{xi} \_\mathrm{c} \\
& \text { taut } \quad=\text { taut }+ \text { tauc } \\
& \text { tau } 1 \quad=\text { taut }
\end{aligned}
$$$$
\text { c }
$$

c

c

$\mathrm{c}$

c

c 


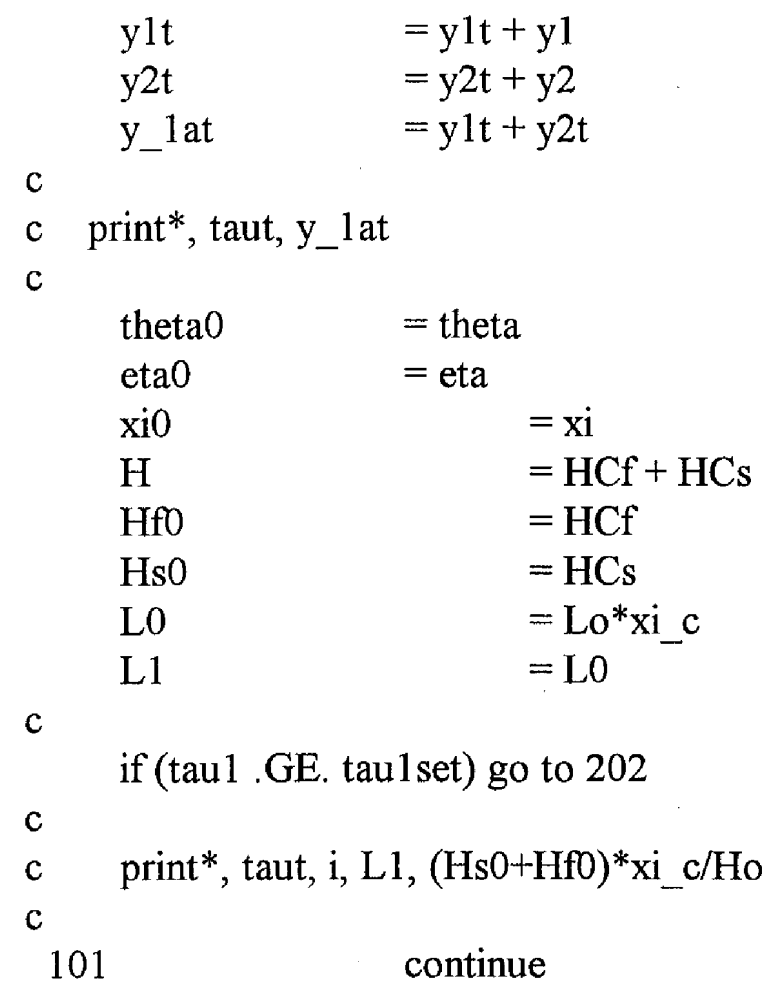


$\mathrm{c}$

$$
\begin{array}{lc}
\text { xi_c } & =x i \_c * x i 0 \\
\text { tauc } & =\operatorname{tau}(3)^{*} \times \text { xi_c }_{-} \\
\text {taut } & =\text { taut }+ \text { tauc } \\
\text { tau2 } & =\text { taut }- \text { tau } 1
\end{array}
$$

c

c convert yield in terms of initial biomass loading -:)

c

$$
\begin{array}{ll}
\mathrm{y} 3 & =\mathrm{y}(3)^{*} \mathrm{HfO}^{*} \mathrm{xi} \mathrm{c} / \mathrm{Ho} \\
\mathrm{y} 4 & =\mathrm{y}(4)^{*} \mathrm{Hs} \mathrm{O}^{*} \mathrm{xi} \_\mathrm{c} / \mathrm{Ho}
\end{array}
$$

\begin{tabular}{|c|c|}
\hline yo2 & $=\left(\mathrm{yo}(3)^{*} \mathrm{HfO}+\mathrm{yo}(4)^{*} \mathrm{Hs} 0\right)^{*} \mathrm{xi} \_\mathrm{c} / \mathrm{Ho}$ \\
\hline $\mathrm{yx} 2$ & $=\left(\mathrm{yx}(3)^{*} \mathrm{HfO}+\mathrm{yx}(4)^{*} \mathrm{Hs} 0\right)^{*} \mathrm{xi} \_\mathrm{c} / \mathrm{Ho}$ \\
\hline yo2t & $=\mathrm{yo} 2+\mathrm{yo} 2 \mathrm{t}$ \\
\hline $\mathrm{yx} 2 \mathrm{t}$ & $=\mathrm{yx} 2+\mathrm{yx} 2 \mathrm{t}$ \\
\hline
\end{tabular}

c

$$
\begin{array}{ll}
\mathrm{y} 3 \mathrm{t} & =y 3 t+y 3 \\
\mathrm{y} 4 \mathrm{t} & =y 4 t+y 4 \\
y \_2 t & =y 3 t+y 4 t
\end{array}
$$

$\mathrm{c}$

c

$\mathrm{c}$

c

theta0 $=$ theta

eta 0 eta

xi0

$=\mathrm{xi}$

$\mathrm{H}=\mathrm{HCf}+\mathrm{HCs}$

HfO $=\mathrm{HCf}$

$\mathrm{HsO} \quad=\mathrm{HCs}$

LO $\quad=$ Lo*xi_c

$\mathrm{L} \quad=\mathrm{L} 0$

$\mathrm{c}$

if (tau2 .GE. tau1) go to 303

$\mathrm{c}$

c print*, taut, L, y_2t+y_1 at, y3t+y4t, yo $2 t+y x 2 t$

$\mathrm{c}$

222 continue

$\mathrm{c}$

c $* * * * * * \quad$ FOR REACTOR 1b, DECOMPOSITION

$\mathrm{C}++++++++++++++++++++++++++++++++++++++++++++++++++++++++++++++++++++$

$++++++++++$

303

taut

xi_c $\quad=1$.

y_lbt

$=0$.

L $\overline{0}=$ Lo

$\mathrm{c}$ 
do $777 \mathrm{i}=1, \mathrm{n}$

c

$$
\begin{array}{ll}
\text { xi_c } & =x i_{-}{ }^{*} x c(i) \\
\text { tauc } & =\operatorname{tau}(1)^{*} x i_{-} c \\
\text { taut } & =\text { taut }+ \text { tauc }
\end{array}
$$

$\mathrm{C}$

call al ga (alpha(1), alpha(2), beta(1), beta(2),

$+$ $\operatorname{gamma}(1), \operatorname{gamma}(2), \operatorname{tem}(1), a, u, L 0)$

c

yo_1b = yo2t/tau $2 * \exp (-\operatorname{alpha}(1) * \operatorname{beta}(1)) * \operatorname{tau}(1)$

yx1_1b $=y x 2 t / \operatorname{tau} 2 * \exp (-\operatorname{gamma}(1) * \operatorname{beta}(1)) * \operatorname{tau}(1)$

yx2_1b = yo2t/tau $2 *(1-\exp (-\operatorname{alpha}(1) * \operatorname{beta}(1))) * \operatorname{tau}(1)$

y_1btc $\quad=\left(\right.$ yo_l $\left.1 \mathrm{~b}+\mathrm{yx} 1 \_1 \mathrm{~b}+\mathrm{yx} 2 \_1 \mathrm{~b}\right) * \mathrm{xi} \_\mathrm{c}$

y_ $1 b t \quad=y_{-} 1 \overline{b t}+y_{-} 1 b_{\overline{t c}}$

c

L0 $\quad$ Lo*xi_c

c

print*, i, taut, y_lat+yo2t+yx2t, y_lat+y_2t, y_lat+y_1bt

c

if (taut .GE. tau1) go to 888

777 continue

888 ty $\quad=y_{-} 1 a t+y_{-} 1 b t$

c

$\mathrm{Cp} \quad=$ ty*Ho/tau 1 set

c

print*, $\mathrm{i}, \mathrm{j}$, tau 1 , taut, ty, Cp, L1, L

open(unit $=3$, file $=$ 'sk. out')

end

$\mathrm{c}$

BEGINING OF SUBROUTINES

$\mathrm{c}$

$\mathrm{c}$

SUBROUTINE TO CALCULATE ALPHA, AND GAMMA

$\mathrm{c}$

subroutine al_ga (alpha1, alpha2, beta1, beta2, gamma1, gamma2,

$+$

tem, a, u, L0)

$\mathrm{c}$

real alphal, gamma1, tem, an(4), k0(4), e(4), k(4), kk(4)

real alpha2, gamma2, beta1, beta2, u, L0

C

c

input kinetic data

c

c $\operatorname{an}(1)=1.0$

c $\quad$ an $(2)=1.0$

c $\operatorname{an}(3)=1.2$

c $\quad$ an $(4)=1.0$ 
c $\quad k 0(1)=1.998 \mathrm{E} 10$

c $\mathrm{k} 0(2)=1.237 \mathrm{E} 13$

c $\mathrm{k} 0(3)=1.046 \mathrm{E} 14$

c $\mathrm{k} 0(4)=8.990 \mathrm{E} 11$

c $\mathrm{e}(1)=20.6 \mathrm{E} 3$

c $\mathrm{e}(2)=27.7 \mathrm{E} 3$

c $\mathrm{e}(3)=27.5 \mathrm{E} 3$

c $\mathrm{e}(4)=28.2 \mathrm{E} 3$

$$
\begin{aligned}
& \operatorname{an}(1)=1.34 \\
& \operatorname{an}(2)=1.0 \\
& \operatorname{an}(3)=1.0 \\
& \operatorname{an}(4)=1.02 \\
& \mathrm{k} 0(1)=1.73 \mathrm{E} 19 \\
& \mathrm{k} 0(2)=1.237 \mathrm{E} 15 \quad \mathrm{k} 0(3)=1.046 \mathrm{E} 14 \\
& \mathrm{k} 0(4)=2.38 \mathrm{E} 14 \quad
\end{aligned}
$$

$\mathrm{e}(1)=42.9 \mathrm{E} 3$

$\mathrm{e}(2)=27.7 \mathrm{E} 3$

$\mathrm{e}(3)=27.5 \mathrm{E} 3$

$\mathrm{e}(4)=32.87 \mathrm{E} 3$

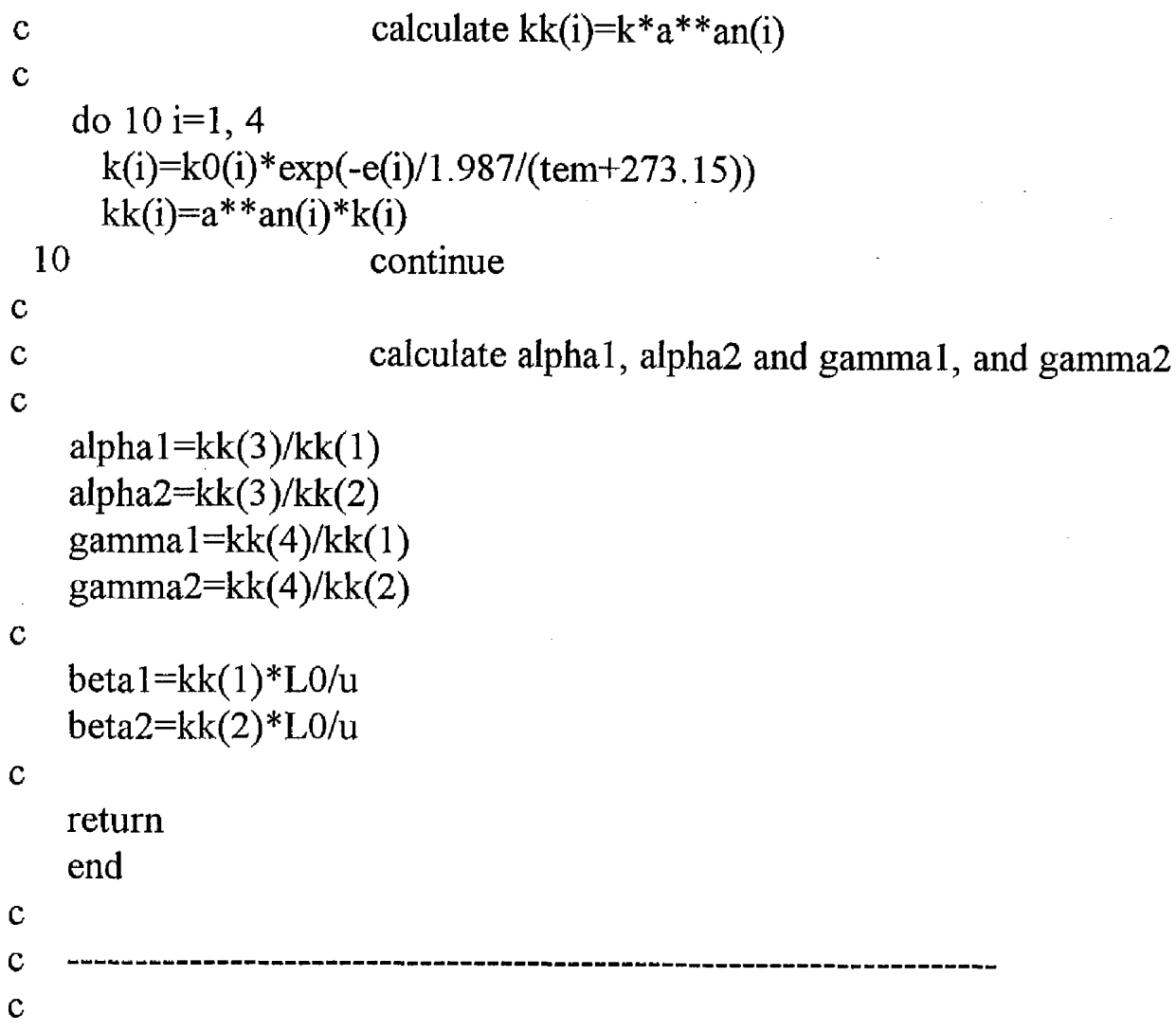


(THETA),

$\mathrm{c}$

$\mathrm{c}$

$\mathrm{c}$

subroutine hemi (theta, eta, xi, HCf, HCs, tau, $+$

real

real

$\mathrm{c}$

c

theta $\quad=1-(\mathrm{Hf}+\mathrm{Hs}) /(\mathrm{HfO}+\mathrm{Hs} 0)$

eta $\quad=($ eta $0 *(1-$ theta $)) /(1-$ eta $0 *$ theta $*(1+$ gara $))$

c

C

$\mathrm{xi}$

c $\quad \mathrm{xi}=1$.

$\mathrm{c}$

$\mathrm{HCf} \quad=\mathrm{Hf} / \mathrm{xi}$

$\mathrm{HCs} \quad=\mathrm{Hs} / \mathrm{xi}$

C

return

end beta1, beta2, theta0, eta0, gara, HfO, HsO)

theta, eta, xi, tau, beta1, beta2, theta 0 , eta 0 , gara

$\mathrm{HCf}, \mathrm{HCs}, \mathrm{HfO}, \mathrm{HsO}$

$=\mathrm{HfO} * \exp (-$ beta $1 *$ tau $)$

$=\mathrm{Hs}^{*} \exp (-$ beta $2 *$ tau $)$ c

C

C

c

c

c

c

C

subroutine yld_1a_2 (yo, yx, alpha, $x$, gamma, tau)

real $\mathrm{yx} 1, \mathrm{yx} 2, \mathrm{yx} 3, \mathrm{yx} 4, \mathrm{yx} 5, \mathrm{yx} 6$

real yo, yx, alpha, $x$, gamma, tau

c

c print*, 'test', $\mathrm{x}$

c

C

$\mathrm{c}$

c

c

$$
\text { yo }=\left(1-\exp \left(-\operatorname{alpha}{ }^{*} \mathrm{x}\right)\right)^{*}
$$

\section{CALCULATE YIELD FROM RECTOR_1a}

calculate xylose oligomer yield 


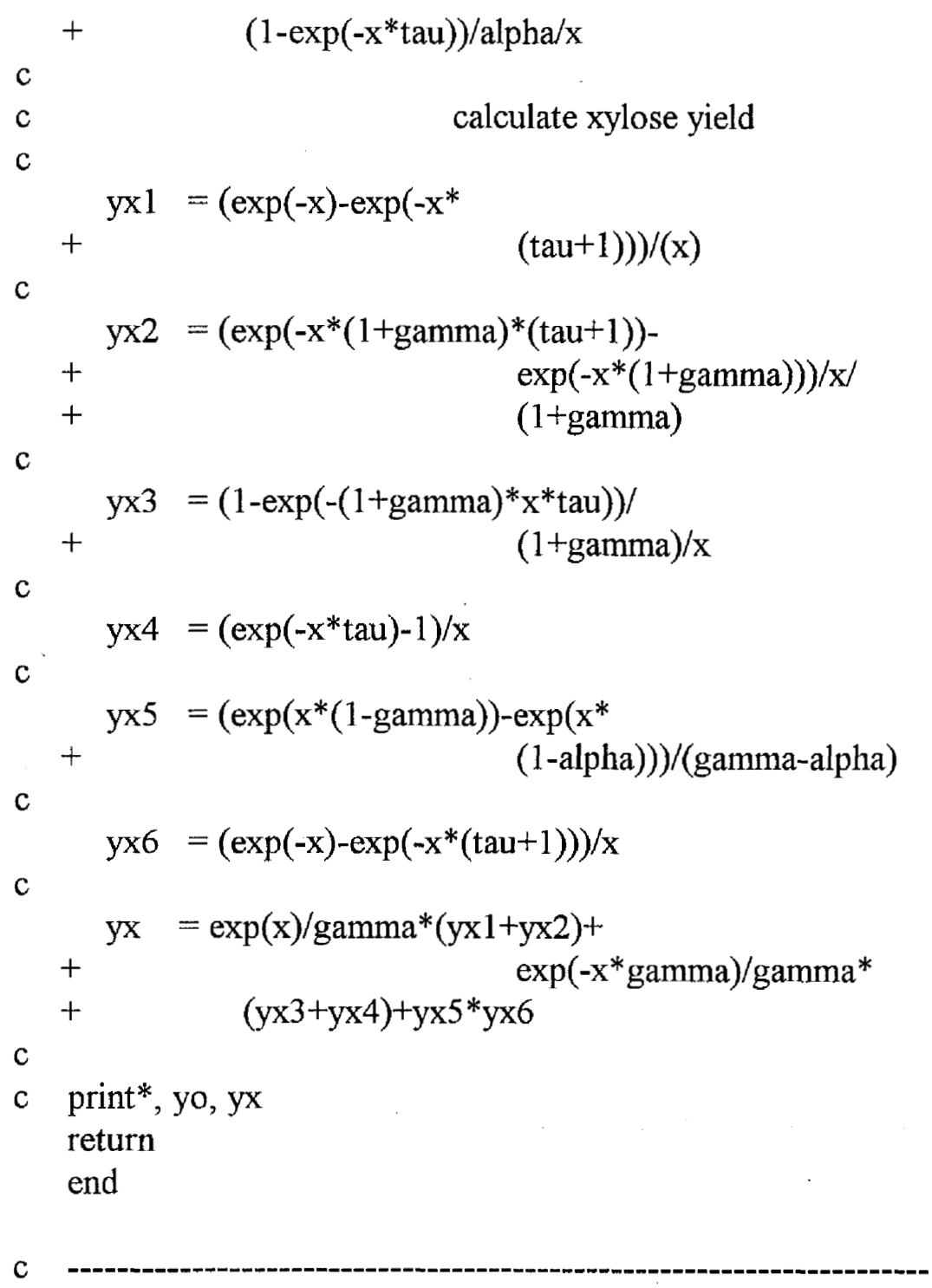




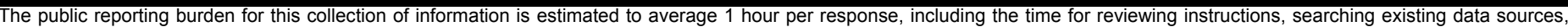

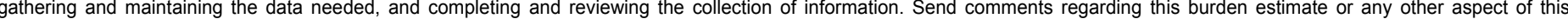

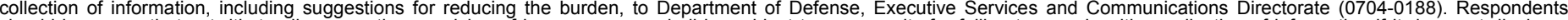

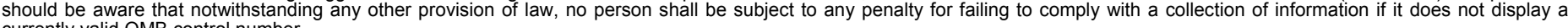

REPORT DOCUMENTATION PAGE
The public reporting burden for this collection of information is estimated to average 1 hour per respo
gathering and maintaining the data needed, and completing and reviewing the collection of informa
collection of information, including suggestions for reducing the burden, to Department of Defense,
should be aware that notwithstanding any other provision of law, no person shall be subject to any $p$
currently valid OMB control number.
PLEASE DO NOT RETURN YOUR FORM TO THE ABOVE ORGANIZATION.

REPORT DOCUMENTATION PAGE
The public reporting burden for this collection of information is estimated to average 1 hour per respo
gathering and maintaining the data needed, and completing and reviewing the collection of informa
collection of information, including suggestions for reducing the burden, to Department of Defense,
should be aware that notwithstanding any other provision of law, no person shall be subject to any $p$
currently valid OMB control number.
PLEASE DO NOT RETURN YOUR FORM TO THE ABOVE ORGANIZATION.

\section{REPORT DATE (DD-MM-YYYY) September 2004 \\ 2. REPORT TYPE \\ Subcontract Report}
4. TITLE AND SUBTITLE
Kinetic and Modeling Investigation on Dilute Sulfuric Acid and Hot
4.
TITLE AND SUBTITLE
Kinetic and Modeling Investigation on Dilute Sulfuric Acid and Hot Water Fractionation of Selected Biomass: May 1997

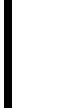

5a. CONTRACT NUMBER
DE-AC36-99-GO10337
5b. GRANT NUMBER

5c. PROGRAM ELEMENT NUMBER

5d. PROJECT NUMBER

NREL/SR-510-36391

5e. TASK NUMBER

BB04.7610

5f. WORK UNIT NUMBER
7. PERFORMING ORGANIZATION NAME(S) AND ADDRESS(ES)

Auburn University

Auburn, Alabama
8. PERFORMING ORGANIZATION REPORT NUMBER

XAW-3-13441-01

9. SPONSORING/MONITORING AGENCY NAME(S) AND ADDRESS(ES)

National Renewable Energy Laboratory

10. SPONSOR/MONITOR'S ACRONYM(S) NREL

1617 Cole Blvd.
Golden, CO 80401-3393

11. SPONSORING/MONITORING AGENCY REPORT NUMBER NREL/SR-510-36391

\section{DISTRIBUTION AVAILABILITY STATEMENT}

National Technical Information Service

U.S. Department of Commerce

5285 Port Royal Road

Springfield, VA 22161

13. SUPPLEMENTARY NOTES

NREL Technical Monitor: R. Torget

14. ABSTRACT (Maximum 200 Words)

Subcontractor developed a processing model to evaluate and optimize an NREL-developed biomass pretreatment technology. The technology, taking advantage of the biphasic nature of hemicellulose in pretreatment, is a two-stage, reverse-flow, shrinking-bed system. The contract simulation found that this system could increase sugar yield by about $5 \%$, with bed shrinkage of $27 \%$ and sugar yield of $95 \%$ at optimum conditions.

15. SUBJECT TERMS

biofuels; ethanol; fuels; chemicals; pretreatment; shrinking bed; hemicellulose; feedstock; biomass

\begin{tabular}{l}
\hline \multicolumn{3}{|l|}{ 16. SECURITY CLASSIFICATION OF: } \\
\hline \begin{tabular}{l|l|l|} 
a. REPORT & b. ABSTRACT & c. THIS PAGE \\
Unclassified & Unclassified & Unclassified \\
& & \\
\hline
\end{tabular} \\
\hline
\end{tabular}

\begin{tabular}{l|l} 
17. LIMITATION \\
OF ABSTRACT \\
UL
\end{tabular}

19a. NAME OF RESPONSIBLE PERSON

19b. TELEPONE NUMBER (Include area code) 